\title{
Transplantation tolerance modifies donor-specific B cell fate to suppress de novo alloreactive $B$ cells
}

\author{
Stella H.W. Khiew, ${ }^{1}$ Dharmendra Jain, ${ }^{1}$ Jianjun Chen, ${ }^{1}$ Jinghui Yang, ${ }^{1}$ Dengping Yin, ${ }^{1}$ James S. Young, ${ }^{1}$ Alexander Dent, ${ }^{2}$ \\ Roger Sciammas, ${ }^{3}$ Maria-Luisa Alegre, ${ }^{4}$ and Anita S. Chong ${ }^{1}$ \\ ${ }^{1}$ Section of Transplantation, Department of Surgery, University of Chicago, Chicago, Illinois, USA. ${ }^{2}$ School of Medicine, Indiana University, Indianapolis, Indiana, USA. ${ }^{3}$ Center for Comparative Medicine, \\ Schools of Medicine and Veterinary Medicine, UC Davis, Davis, California, USA. ${ }^{4}$ Section of Rheumatology, Department of Medicine, University of Chicago, Chicago, Illinois, USA.
}

\begin{abstract}
The absence of alloantibodies is a feature of transplantation tolerance. Although the lack of $\mathrm{T}$ cell help has been evoked to explain this absence, herein we provide evidence for B cell-intrinsic tolerance mechanisms. Using a murine model of heart tolerance, we showed that alloreactive B cells were not deleted but rapidly lost their ability to differentiate into germinal center B cells and secrete donor-specific antibodies. We inferred that tolerant alloreactive B cells retained their ability to sense alloantigen because they continued to drive T cell maturation into CXCR5 $+\mathrm{PD}-1^{+} \mathrm{T}$ follicular helper cells. Unexpectedly, dysfunctional alloreactive B cells acquired the ability to inhibit antibody production by new naive B cells in an antigen-specific manner. Thus, tolerant alloreactive B cells contribute to transplantation tolerance by foregoing germinal center responses while retaining their ability to function as antigen-presenting cells and by actively suppressing de novo alloreactive B cell responses.
\end{abstract}

\section{Introduction}

Donor-specific antibodies (DSAs) are barriers to long-term graft acceptance by mediating antibody-mediated rejection through direct binding to the allograft (1) or generating opsonins that enhance antigen-presenting cell (APC) activation and amplify alloreactive $\mathrm{T}$ and $\mathrm{B}$ cell responses (2). In hematopoietic cellmediated tolerance to kidney allografts in the clinic (3), early DSA production prevented the induction of tolerance, while late DSA production was detrimental to tolerance maintenance. There is limited mechanistic understanding of how DSA production is controlled during stable transplantation tolerance. Using 3.83 B cell receptor-knockin (BCR-knockin) mice, we previously reported clonal deletion as a major mechanism of alloreactive B cell tolerance (4). However, 95\% or greater of B cells express the 3.83 BCR in these recipients (5), thus raising concerns that the abnormally large numbers of cells with identical BCRs might have contributed to the observed deletion (6). We subsequently reported that in non-BCR-Tg recipients, depletion of regulatory $\mathrm{T}$ cells (Tregs) resulted in allograft rejection but failed to restore DSA production by endogenous tolerant B cells (7). However, we were not able to ascertain if the endogenous donor-specific B cells had been deleted or were intrinsically unable to produce DSA. Subsequently, Parsons et al. (8) developed a synchimeric mouse model to reduce the frequency of 3.83 BCR-Tg B cells, and reported that when 3.83 cells encountered allogeneic heart grafts, they acquired a devel-

Related Commentary: p. 3406

Conflict of interest: The authors have declared that no conflict of interest exists. Copyright: (5) 2020, American Society for Clinical Investigation.

Submitted: August 19, 2019; Accepted: March 11, 2020; Published: May 26, 2020.

Reference information: J Clin Invest. 2020;130(7):3453-3466.

https://doi.org/10.1172/JCl132814. opmentally arrested phenotype $\left(\operatorname{IgM}{ }^{\mathrm{lo}} \mathrm{CD} 21 / 35^{\mathrm{lo}}\right)$ reminiscent of autoantigen-driven anergic peripheral $\mathrm{B}$ cells.

In this study, we optimized a technique based on the use of major histocompatibility complex (MHC) class I tetramers to track endogenous donor-MHC-reactive B cells (9). Because recipient B cells encounter vastly different amounts of MHC class I versus class II antigens that may result in divergent mechanisms of tolerance, we incorporated the use of donor MHC class II tetramers $(10,11)$. We used 2 tetramer-binding assays, 2 approaches for inducing allograft acceptance, and the adoptive transfer (AdTr) of B cells into 2 different hosts (BCR-Tg hosts harboring B cells of irrelevant specificity or congenic hosts) to show that in transplantation-tolerant recipients, donor-specific B cells develop a state of cell-intrinsic dysfunction and are unable to differentiate into germinal center (GC) B cells even when donor-specific $\mathrm{T}$ follicular helper ( $\mathrm{Tfh}$ ) cells are present. Remarkably, these tolerant B cells acquired the ability to suppress new naive $B$ cell antibody responses in an antigen-specific manner. To avoid assumptions stemming from other previously investigated states of B cell dysfunction or regulatory B cells (Bregs) that suppress T cells, we refer to these as "tolerant" B cells.

\section{Results}

$B$ cell tolerance in $B A L B / c$ heart transplant recipients treated with anti-CD154 and DSCs is not due to clonal deletion. The absence of DSAs is often associated with stable allograft tolerance. In a model of full MHC-mismatched and minor antigen-mismatched heart transplant (HTx), anti-CD154 antibody plus donor spleen cells (costimulation blockade [CoB/DSC]) induced long-term $\mathrm{BALB} / \mathrm{c}(\mathrm{B} / \mathrm{c}$ ) allograft survival in C57BL/6 (B6) recipients, with essentially no detectable DSA responses (Figure $1, A-C$ ). The inability to generate DSAs in tolerant recipients could be due to clonal B cell deletion, continued absence of $\mathrm{T}$ cell help, and/or B cell-intrinsic dysfunction. To test for clonal deletion, we optimized 
A

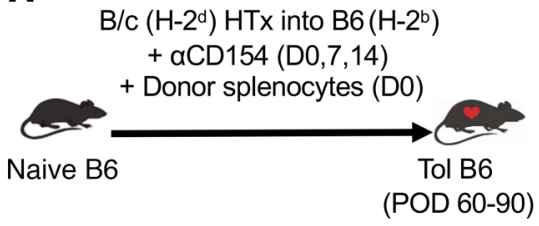

B

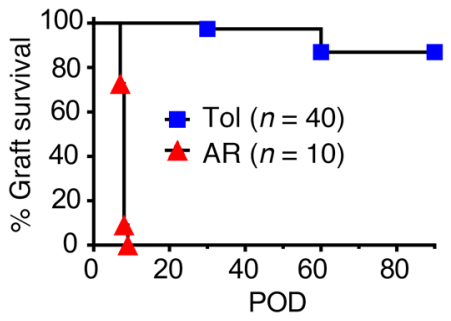

C

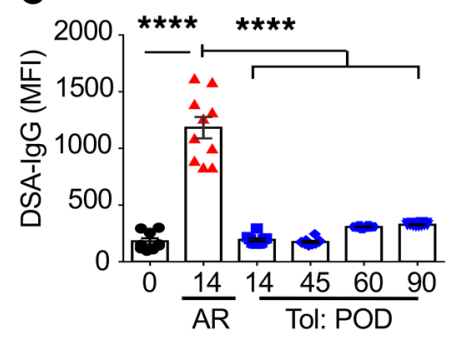

D

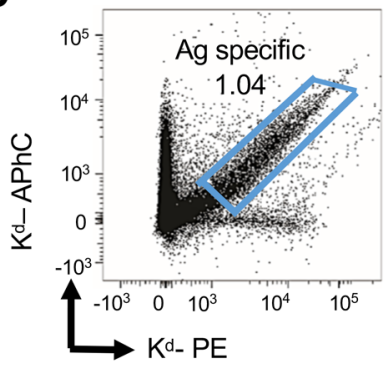

E

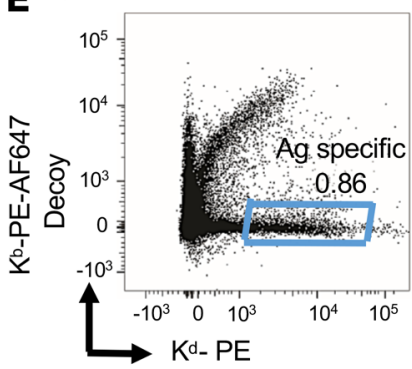

$\mathbf{F}$

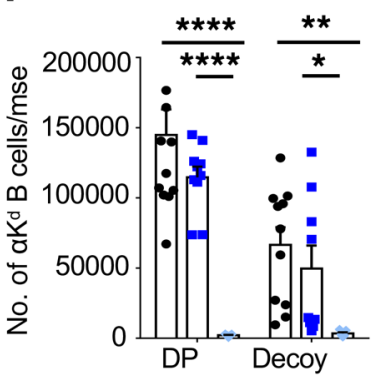

I

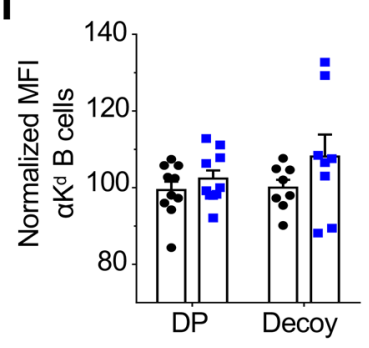

G

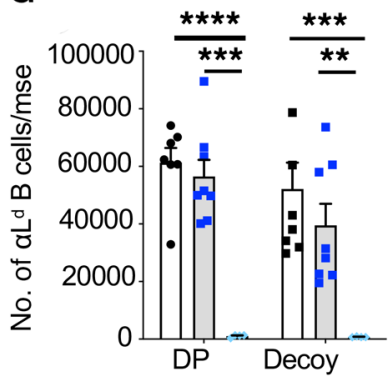

H

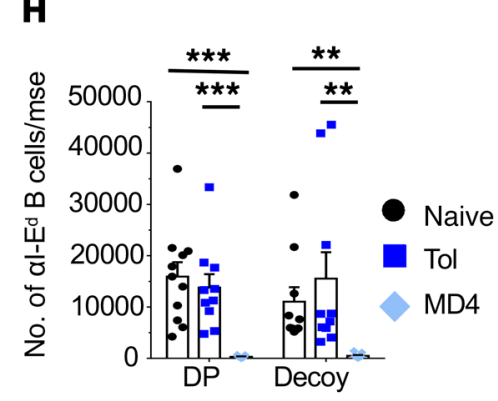

J

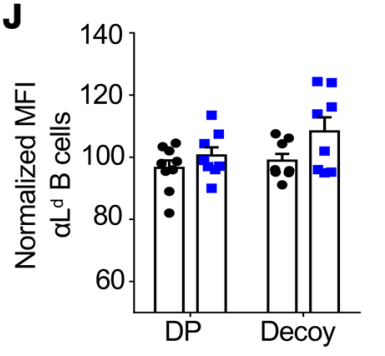

K

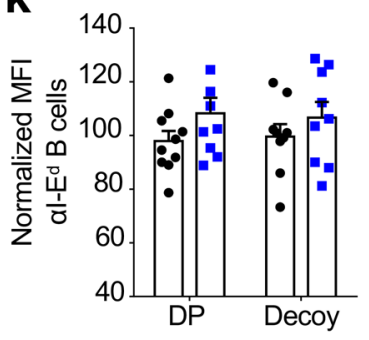

Figure 1. Alloreactive B cells are not deleted in tolerant recipients. (A) $B / c\left(H-2^{d}\right)$ or $B / c .2 W-O V A$ heart allografts were transplanted into $C 57 B L / 6$ (B6, $\mathrm{H}-2^{\mathrm{b}}$ ) recipients that were untreated (acutely rejecting, AR) or treated with anti-CD154 ( $\alpha$ CD154) on day 0 (DO), D7, and D14 plus DSCs (DO) to induce allograft tolerance. (B) Survival of allograft in AR or tolerant (Tol) mice. $n=10-40 /$ group; $P<0.0001$ by log-rank test. (C) Donor-specific antibodies-lgG (DSA-IgG) from Tol mice on postoperative day (POD) 0, 14, 45, 60, and 90 after heart transplant (HTx) and AR D14. $n=9-12 /$ group. Representative flow plots of $\mathrm{H}-2 \mathrm{~K}^{\mathrm{d}}$-binding $\mathrm{B}$ cells in naive $\mathrm{B} 6$ mice were identified using (D) double-positive (DP) donor MHC class I ( $\mathrm{K}^{\mathrm{d}}$ ) tetramer conjugated to PE or APhC fluorochromes, and $(\mathbf{E})$ decoy $\mathrm{K}^{\mathrm{b}}$ (recipient $\mathrm{MHC}$ ) tetramer conjugated to $\mathrm{PE}$ and AF647 in combination with $\mathrm{K}^{\mathrm{d}}-\mathrm{PE}$ tetramers. (F-H) Splenocytes and inguinal, axillary, and branchial lymph node cells were pooled and the total number of $(\mathbf{F}) \mathrm{K}^{\mathrm{d}},(\mathbf{G}) \mathrm{L}^{\mathrm{d}}$, and $(\mathbf{H}) \mathrm{I}-\mathrm{E}^{\mathrm{d}}$ tetramer-binding $B$ cells from naive, Tol, or naive MD4 (anti-HEL BCR-Tg) mice were analyzed. $n=4-12$ /group. mse, mouse. (I-K) Normalized mean fluorescence intensity (MFI) of (I) K ${ }^{d}$, (J) $L^{d}$, and (K) I-E tetramer-specific B cells from naive and Tol mice. $n=6-10 /$ group. MFIs were normalized to DP or decoy tetramer-binding B cells of naive B6 mice. Data were pooled from 2 or more independent experiments and are presented as the mean \pm SEM. ${ }^{*} P<0.05$; ${ }^{* *} P<0.01 ;{ }^{* *} P<0.001$; ${ }^{* * * *} P<0.0001$ by 2 -way ANOVA with Tukey's post hoc test for multiple comparisons (F-H) or 1-way ANOVA with Bonferroni's post hoc test (C).

the approach in which MHC class I tetramers were conjugated to 2 different fluorochromes, phycoerythrin (PE) and allophycocyanin (APhC), and the double-positive cells were considered to be enriched for donor-MHC-specific B cells (Figure 1D and ref. 10). Furthermore, because each tetramer harbors additional nonMHC epitopes, including human $\beta 2$-microglobulin, streptavidin, biotin, and a $6 \times$ HIS-tag, we used a second approach in which $\mathrm{B}$ cells that were reactive to these components were identified as binding to the decoy $\mathrm{K}^{\mathrm{b}}$ (recipient $\mathrm{MHC}$ ) tetramer conjugated to both PE and Alexa Fluor 647 (AF647) (Figure 1E and refs. 12, 13). The decoy tetramer was incubated at 6-fold higher concentration, and before the addition of $\mathrm{K}^{\mathrm{d}}$-PE tetramers, to further optimize the identification of $\mathrm{K}^{\mathrm{d}}$-specific B cells (Figure 1D). We also used a second donor class $\mathrm{I}\left(\mathrm{H}-2 \mathrm{~L}^{\mathrm{d}}\right)$ tetramer, and donor I- $\mathrm{E}^{\mathrm{d}}$ tetramers (11) to track donor-MHC class II-specific B cells. We observed comparable alloreactive $\mathrm{B}$ cells numbers in $\mathrm{B} 6$ naive and tolerant mice using the double-positive and decoy tetramer approach. Furthermore, the B cells bound to donor-MHC tetramers with similar mean fluorescence intensity (MFI) (Figure 1, F-K). We observed an approximately 20 -fold reduction in the total number of alloreactive $\mathrm{B}$ cells in BCR-Tg MD4 mice compared with wild-type (WT) B6 mice, consistent with 95\% of B cells in MD4 mice having specificity for hen egg lysozyme (HEL) (14).

Comparable numbers of B cells from B6 naive versus tolerant mice bound to tetramers with high, medium, and low MFI, suggested a lack of deletion of high-affinity alloreactive B cells in tolerant recipients (Supplemental Figure 1; supplemental material available online with this article; https://doi. org/10.1172/JCI132814DS1). To further confirm this conclusion, we assessed dose-dependent BCR signaling upon donor I- $\mathrm{E}^{\mathrm{d}}$ tetramer binding, by quantifying the induced expression of CD69 and the transcription factors Nur77 and IRF4 (15-17). 
A

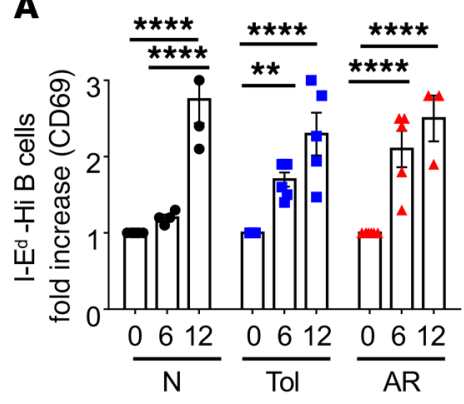

B

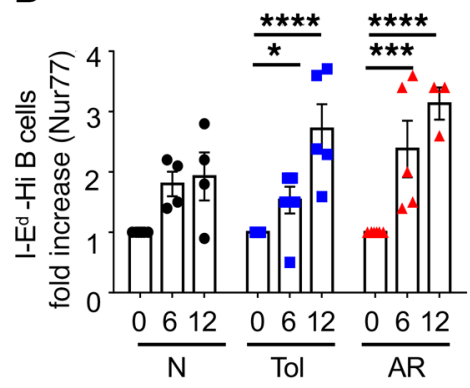

C

D

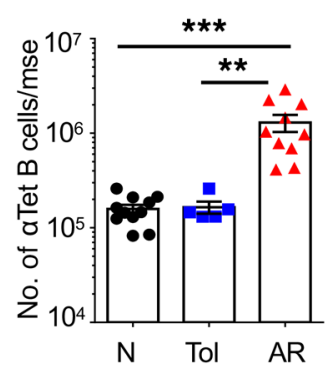

H

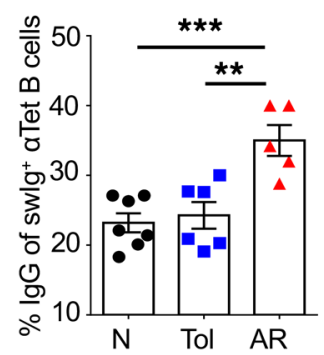

E

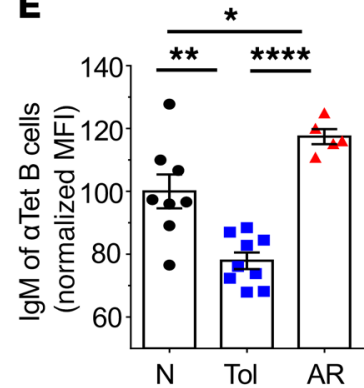

$\mathbf{F}$

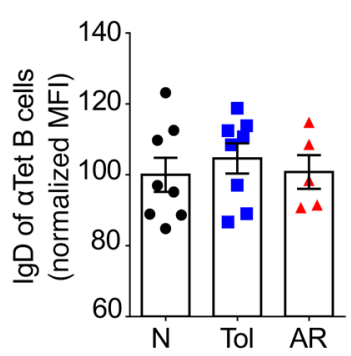

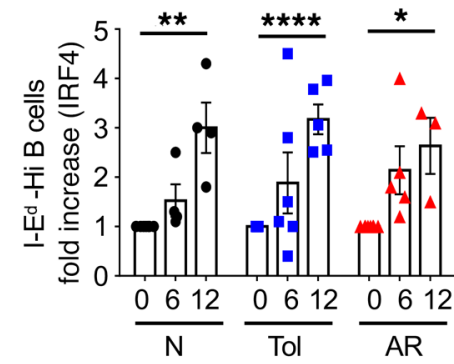

G

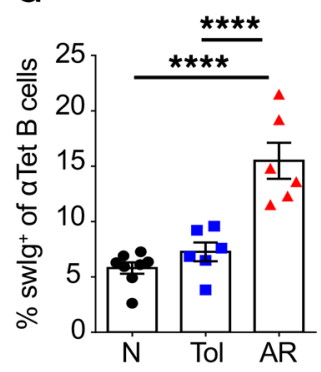

I

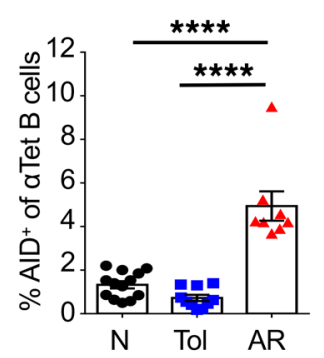

$\mathbf{J}$

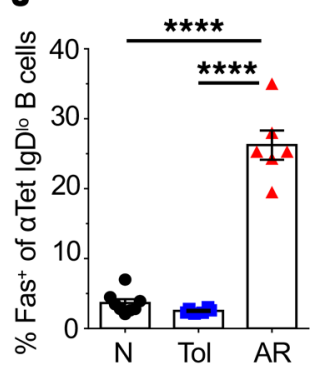

K

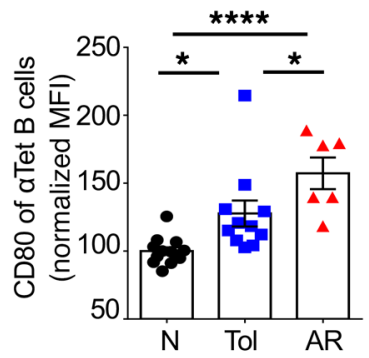

Figure 2. Alloreactive B cells in tolerant recipients express early activation markers but do not differentiate into germinal center $B$ cells. Fold increase in the percentage of early activation markers (A) CD69, (B) Nur77, and (C) IRF4, after coculture with immobilized I-Ed tetramer for 6 or 12 hours. B cells that bound to I- $E^{d}$ tetramer with high MFI were sorted from naive (N), tolerant (Tol) (day $\geq 30$ after HTx), and AR (days 10-14 after HTx) mice. $n=4-6 / g r o u p$. Data were normalized to unstimulated I- $E^{d}$ tetramer-negative B cells cultured for 6 or 12 hours. (D) Total number of donor-specific (anti-K $K^{d}\left[\alpha K^{d}\right], \alpha L^{d}$, and $\alpha$ l-Ed) B cells/mouse (mse). $n=5$-11/group. (E) IgM expression of anti-tetramer ( $\alpha$ Tet) B cells. $n=5$-9/group. (F) IgD of $\alpha$ Tet B cells. $n=5-8 /$ group. (C) Percentage switched immunoglobulin-positive (swlg') of $\alpha$ Tet B cells. $n=6-8 /$ group. (H) Percentage IgG of swlg $\alpha$ Tet B cells. $n=5-7 / g r o u p$. (I) Percentage AID+ of $\alpha$ Tet B cells. $n=8-13$ /group. (J) Percentage Fas ${ }^{+}$of $\alpha$ Tet IgD ${ }^{10}$ B cells. $n=6-8 /$ group. (K) CD80 expression on $\alpha$ Tet B cells ( $n=6-13 /$ group) in naive, tolerant, and AR mice. MFIs were normalized to naive control mice. Each symbol represents an individual mouse, pooled from 2 or more independent experiments. Data are presented as the mean $\pm \mathrm{SEM}$. ${ }^{*} P<0.05 ;{ }^{* *} P<0.01 ;{ }^{* *} P<0.001 ;{ }^{* * *} P<0.0001$ by 1 -way ANOVA with Bonferroni's post hoc test.

First, B cells from naive B6 mice were flow sorted into I-E $\mathrm{E}^{\mathrm{d}}$ tetramer-binding B cells of high or low MFI, and then cultured them at $37^{\circ} \mathrm{C}$ for 6 or 12 hours (Supplemental Figure 2A). Data were normalized to fold-increase in percentage of cells expressing CD69, Nur77, and IRF4 relative to unstimulated non-I-Ed tetramer-binding (Tet-Neg) B cells. A higher percentage of I-E - Hi B cells compared with I-Ed-Lo B cells was induced to express CD69, Nur77, and IRF4, consistent with tetramer MFI correlating with BCR signaling intensity (Supplemental Figure 2, B and C). We next determined the percentage of $\mathrm{I}-\mathrm{E}^{\mathrm{d}}$ tetramer-binding $\mathrm{B}$ cells from naive, acutely rejecting (AR) (days 7-10 after $\mathrm{HTx}$ ), or tolerant B6 mice ( $\geq$ day 30 after $\mathrm{HTx}$ ) that were induced by I- $E^{d}$ tetramers to upregulate CD69, Nur77, and IRF4. Tet-Neg B cells stimulated with anti-IgM F $(a b)_{2}$ were positive controls (Supplemental Figure 2, D-F). Comparable induction of CD69, Nur77, and IRF4 was observed with I-Ed-Hi
$\mathrm{B}$ cells from naive, tolerant, and AR mice, consistent with a lack of deletion of higher-affinity alloreactive $B$ cells in tolerant compared with naive mice (Figure 2, A-C). These observations also suggest that tolerant $\mathrm{B}$ cells can respond to $\mathrm{BCR}$ signaling comparably to $B$ cells of naive or AR recipients.

Phenotypic analysis of $B$ cells in tolerant mice. More extensive phenotypic analysis was performed on alloreactive B cells from naive or tolerant mice. Positive control, AR recipients (days 10-14 after HTx) had approximately 10-fold more alloreactive B cells (specific for $\mathrm{K}^{\mathrm{d}}, \mathrm{L}^{\mathrm{d}}$, and $\mathrm{I}-\mathrm{E}^{\mathrm{d}}$ tetramers) compared with naive or tolerant B6 mice (day $\geq 30$ after HTx). Tolerant B cells exhibited modest but significantly reduced expression of surface IgM relative to naive or AR B cells, whereas the levels of IgD were comparable between all 3 groups (Figure 2, D-F). The percentages of class-switched or $\operatorname{IgG}^{+}$of tetramer-binding alloreactive B cells were comparable between naive and tolerant recipients, but sig- 
A

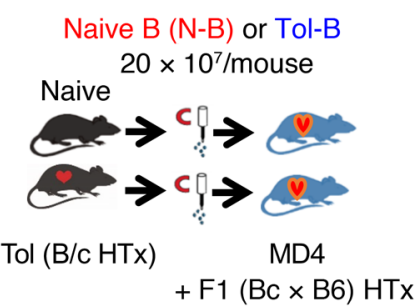

B

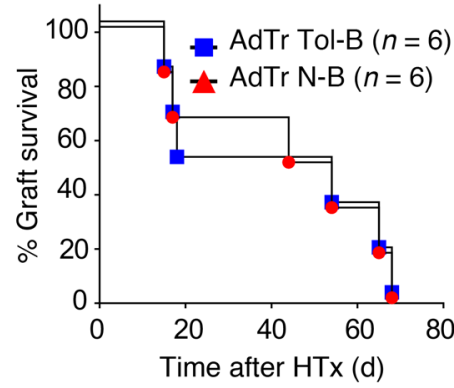

C

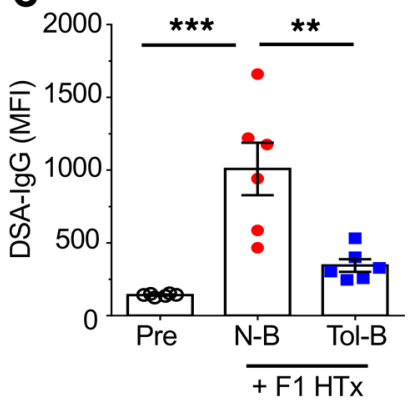

D

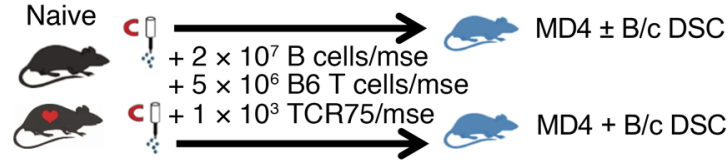

Tol (B/c HTx)

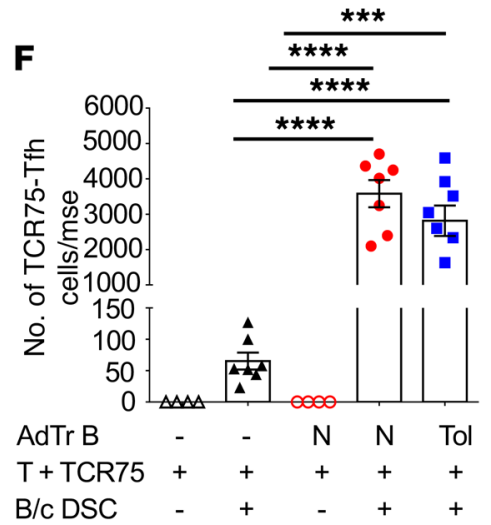

\section{E}

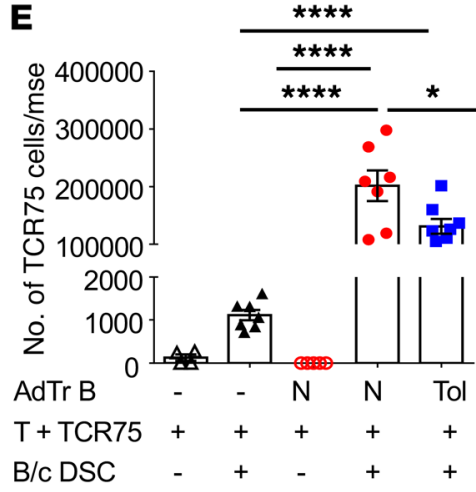

2000 $\begin{array}{ll}\text { ㅎ․ } & 2000 \\ \text { ㅇ } & 1000\end{array}$ AdTr B 0 $\mathrm{T}+\mathrm{TCR} 75++\quad+\quad+$ $\mathrm{B} / \mathrm{c}$ DSC

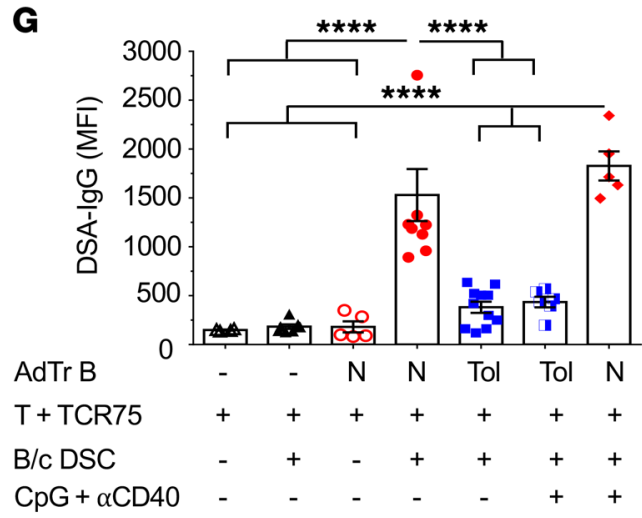

Figure 3. Tolerant B cells exhibit cell-intrinsic dysfunction. (A) Experimental design. Enriched B cells $\left(2 \times 10^{7}\right)$ isolated from naive (N-B) or tolerant (Tol-B) mice were transferred into MD4 hosts and challenged with $\mathrm{F} 1(\mathrm{~B} / \mathrm{C} \times \mathrm{B} 6)$ heart allografts the following day. (B) F1 heart-graft survival in MD4 mice receiving $\mathrm{N}-\mathrm{B}$ cells or Tol B cells. $n=6 /$ group. (C) DSAIgC (MFI) analyzed at the time of graft rejection. $n=6 /$ group. (D) Experimental design. Purified 2 $\times 10^{7} \mathrm{~N}$-B cells or Tol-B cells were adoptively transferred (AdTr) together with $5 \times 10^{6}$ enriched B6 T cells and $1 \times 10^{3}$ TCR75 T cells into MD4 mouse (mse) hosts, followed by immunization with $2 \times 10^{7} \mathrm{~B} / \mathrm{c}$ donor spleen cells (DSCs). (E) Total number of TCR75 T cells/mouse analyzed on day 14. $n=4-8$ /group. (F) Total TCR75-Tfh cells/mouse. $n=4-8$ / group. (C) DSA-IgG (MFI) from $\mathrm{N}$-B-cell or Tol-B-cell recipients immunized with or without $2 \times$ $10^{7} \mathrm{~B} / \mathrm{c}$ DSCs with or without $\mathrm{CpC}$ $(100 \mu \mathrm{g} /$ mouse i.v. given on day 0 , and $50 \mu \mathrm{g} /$ mouse i.p. on days 1 and 2 ) plus anti-CD40 ( $\alpha$ CD40; $100 \mu \mathrm{g} /$ mouse i.v. on days 0 and 7) on day 14 after AdTr. $n=$ 4-11/group. Data were pooled from 2 or more independent experiments. Data are presented as the mean \pm SEM. ${ }^{*} P<0.05$; ${ }^{*} P<0.01$; ${ }^{* *} P<0.001$; ${ }^{* * *} P$ $<0.0001$ by 1 -way ANOVA with Bonferroni's post hoc test. nificantly reduced relative to $B$ cells from AR mice (Figure 2, $G$ and $\mathrm{H})$. Likewise, tolerant B cells expressed comparable levels of cytidine deaminase (AID) and $\mathrm{Fas}^{+} \mathrm{GC}$ phenotype to those of naive B cells, which were significantly lower than AR B cells. (Figure 2, I and J). Finally, tolerant donor-specific B cells modestly upregulated CD80, the glucose transporter Glut-1 (18), and the proliferation marker Ki-67, but had reduced mitochondrial mass compared with naive counterparts (Figure 2K and Supplemental Figure 3). The expression of CD40 on tolerant donor-specific B cells was comparable to naive and modestly reduced relative to that from presensitized mice (Supplemental Figure 3, D and E). These data are consistent with tolerant $\mathrm{B}$ cells having encountered alloantigen but were arrested in their differentiation into GC B cells.

$B$ cell tolerance is due to $B$ cell-intrinsic dysfunction. To test whether the inability of $B$ cells from tolerant mice to produce alloantibodies was B cell intrinsic, we transferred tolerant or naive B cells into MD4 hosts receiving allogeneic $\mathrm{F} 1(\mathrm{~B} / \mathrm{c} \times \mathrm{B} 6) \mathrm{HTx}$ (Figure $3 \mathrm{~A})$. MD4 hosts have a reduced repertoire of $\mathrm{B} / \mathrm{c}$-reactive $\mathrm{B}$ cells
(Figure 1, F-H), so AdTr B cells are the main source of alloreactive $\mathrm{B}$ cells and DSA. Allogeneic hearts were rejected at comparable rates by MD4 hosts receiving tolerant or naive $\mathrm{B}$ cells (Figure 3B); however, significantly reduced $\mathrm{B} / \mathrm{c}$-specific $\operatorname{IgG}$ was produced in hosts receiving tolerant $\mathrm{B}$ cells (Figure $3 \mathrm{C}$ ). These data confirmed that donor-specific $\mathrm{B}$ cells acquire a cell-intrinsic tolerant state in HTx recipients treated transiently with $\mathrm{CoB} / \mathrm{DSC}$, which is maintained upon AdTr despite acute allograft rejection.

To investigate whether AdTr tolerant B cells were unable to produce DSA despite $\mathrm{T}$ cell help, $2 \times 10^{7}$ tolerant or naive $\mathrm{B}$ cells were transferred into MD4 hosts $-2 \times 10^{7}$ was experimentally determined to be the minimal number of naive $\mathrm{B}$ cells necessary to ensure a donor-specific IgG response in all the MD4 hosts immunized with $\mathrm{B} / \mathrm{c}$ spleen cells. $\mathrm{B}$ cells from naive and tolerant HTx recipients (postoperative day $[\mathrm{POD}] \geq 30$ ) were AdTr with 5 $\times 10^{6}$ polyclonal B6 T cells and $1 \times 10^{3} \mathrm{TCR} 75 \mathrm{~T}$ cells (Figure 3D). TCR75 $\mathrm{T}$ cells recognize donor-derived $\mathrm{K}^{\mathrm{d}}$ peptide presented on recipient $\mathrm{I}-\mathrm{A}^{\mathrm{b}}$, and thus are able to engage in cognate interactions 
A

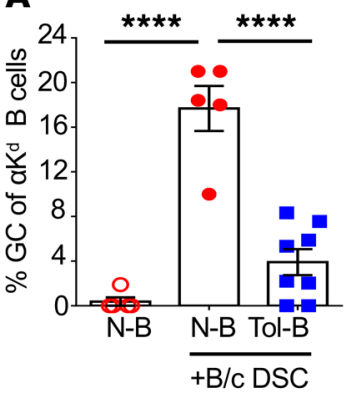

B

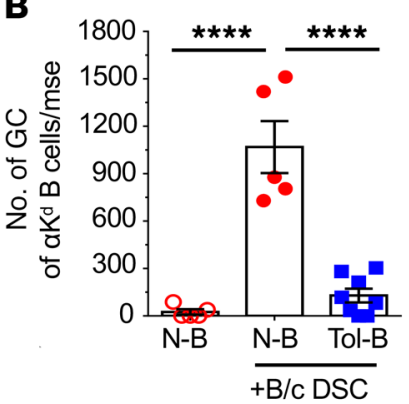

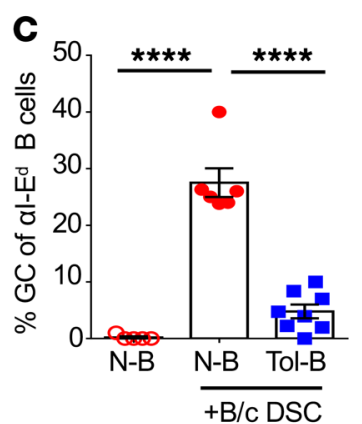

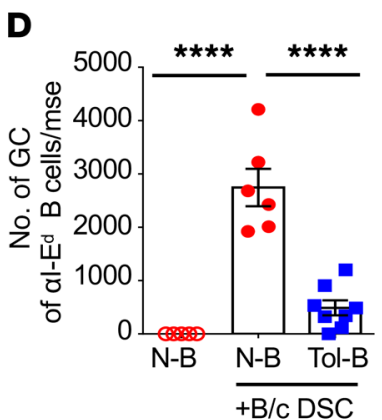

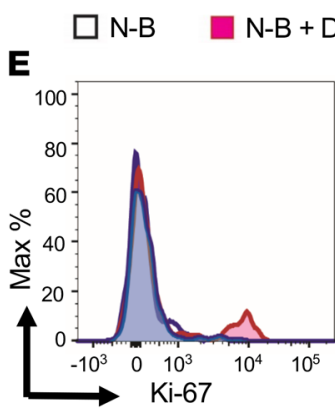

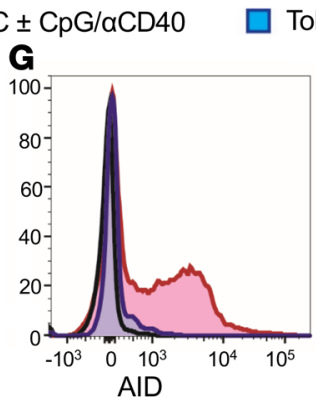

Tol-B + DSC \pm CpG/aCD40

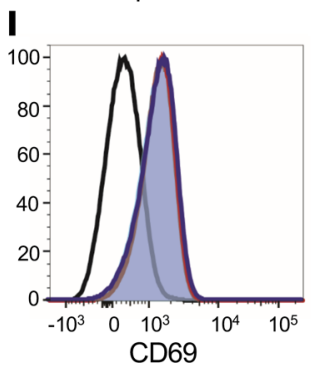

K

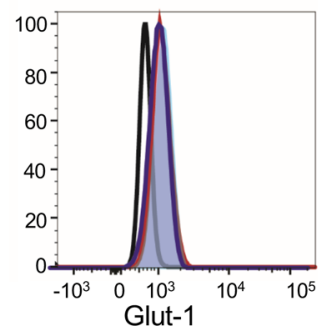

M

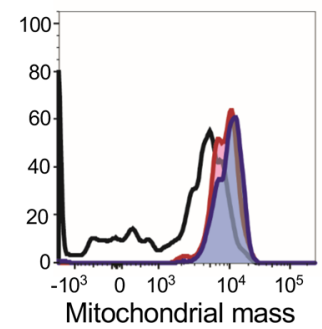

F

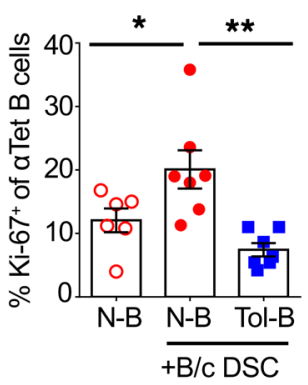

H

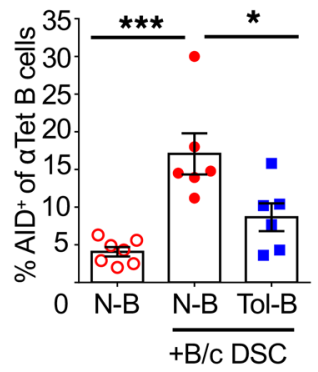

J

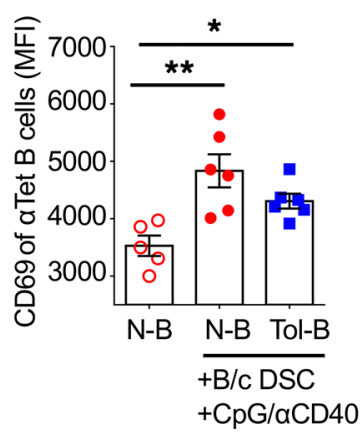

L

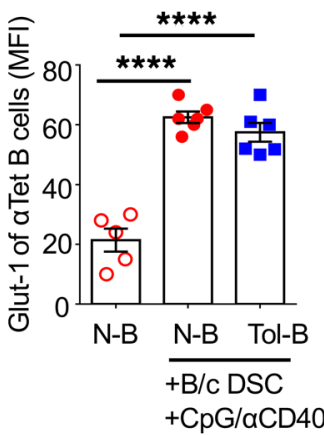

$\mathbf{N}$

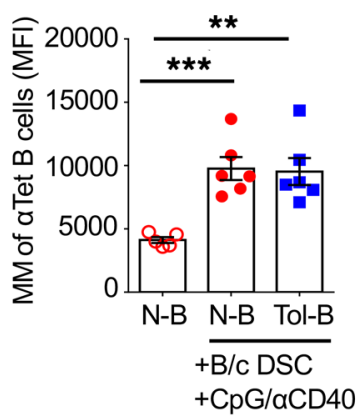

Figure 4. In the presence of cognate T cells, adoptively transferred, tolerant, alloreactive B cells express early activation markers but have reduced GC differentiation. Spleens and inguinal, axillary, and branchial lymph nodes (LNs) were harvested from MD4 hosts that received $2 \times 10^{7} / \mathrm{mouse}$ naive $B(N-B)$ cells or tolerant B (Tol-B) cells followed by immunization with $2 \times 10^{7}$ B/c DSCs and analyzed on day 14 after AdTr. (A) Percentage GCs of anti-Kd $\left(\alpha K^{d}\right) B$ cells. (B) Total number of GCs of $\alpha K^{d} B$ cells/mouse (mse). (C) Percentage GCs of $\alpha /-E^{d} B$ cells. (D) Total number of GCs of $\alpha$ l-E $B$ cells $/ m o u s e . n=$ 5-8/group. (E-H) Representative histograms and percentage of (E and F) Ki-67+ anti-tetramer ( $\alpha$ Tet) B cells and (G and $\mathbf{H})$ AID ${ }^{+} \alpha$ Tet B cells. $n=6-7 / g r o u p$. (I-N) Representative histograms and MFI of (I and J) CD69, ( $\mathbf{K}$ and $\mathbf{L}$ ) Glut-1, and ( $\mathbf{M}$ and $\mathbf{N}$ ) mitochondrial mass (MM) of $\alpha$ Tet B cells from the spleens and LNs harvested from MD4 mice that received N-B and Tol-B cells on day 3 after AdTr, and then immunized with $2 \times 10^{7} \mathrm{~B} / \mathrm{C} \mathrm{DSCs} \mathrm{plus} \mathrm{CpG.} n=5-6 / \mathrm{group}$. Data were pooled from 2 independent experiments. Data are presented as the mean $\pm \mathrm{SEM}$. ${ }^{*} P<0.05 ;{ }^{* *} P<0.01 ;{ }^{* *} P<0.001$; ${ }^{* * * *} P<0.0001$ by 1 -way ANOVA with Bonferroni's post hoc test.

with $\mathrm{K}^{\mathrm{d}}$-specific B cells (19). In the absence of DSC immunization, comparable numbers of total and donor-specific B cells were recovered on day 14 after AdTr (Supplemental Figure 4, A and B). Following B/c DSC immunization, MD4 mice receiving naive or tolerant $\mathrm{B}$ cells had significant and comparable accumulation of total TCR75 T cells, including those with a CXCR5 ${ }^{+}$PD $-1^{\text {hi }}$ Tfh phenotype (Figure 3, E and F). Importantly, the numbers of TCR75 and TCR75-Tfh cells were significantly higher in mice receiving AdTr B cells compared with immunized MD4 mice that did not receive AdTr B cells, consistent with AdTr B cells driving TCR75 expansion and differentiation. Notably, MD4 mice receiving tolerant B cells produced significantly reduced DSA-IgG compared with those receiving naive $B$ cells (Figure $3 G$ ). These observations suggest that donor-specific B cells are not deleted during toler- ance, retained the ability to functionally interact with cognate $\mathrm{T}$ cells and drive their clonal expansion and Tfh differentiation, but were intrinsically blocked in their differentiation into GC B cells. Tolerant B cells also differ from quiescent memory B cells, which upon AdTr into congenic B6 mice and immunization with $\mathrm{B} / \mathrm{c}$ DSCs produced more donor-specific IgG, and with faster kinetics, compared with naive B cells (20).

Finally, despite comparable levels of CD40 expression by AdTr tolerant and naive B cells (Supplemental Figure 4, D and E), reduced DSA production by tolerant B cells was observed in MD4 mice treated with agonistic anti-CD 40 antibody plus $\mathrm{CpG}$ at doses capable of preventing anti-CD154/DSC-induced tolerance (21) and of stimulating polyclonal B cell activation (Figure 3G and Supplemental Figure 5). Thus, tolerant B cells transferred into naive 
A

Naïve

(F) $\pm(\alpha$ CD154 + DSC $)+2 \times 10^{7} \mathrm{~B}$ cells $/ \mathrm{mse}$

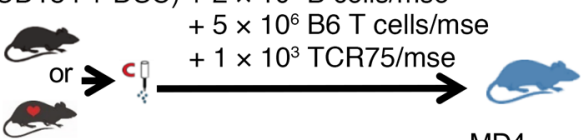

MD4

(B,F) Tol ( $\alpha$ CD154 + DSC)

(C) Tol $(\alpha \mathrm{CD} 154+\mathrm{DSC})$ $+\alpha \mathrm{CD} 40$ (D0)

(D) HTx + CTLA-4Ig (D0,2,4,7)

(E) Tol ( $\alpha$ CD154 + DSC), sac on D7, $14,35,>60$ after HTx

D

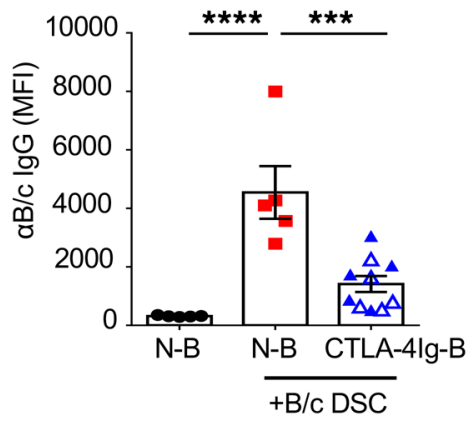

B

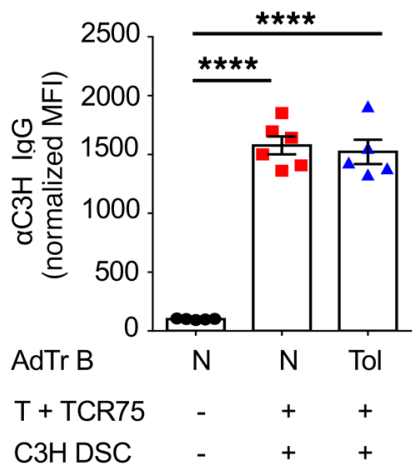

C

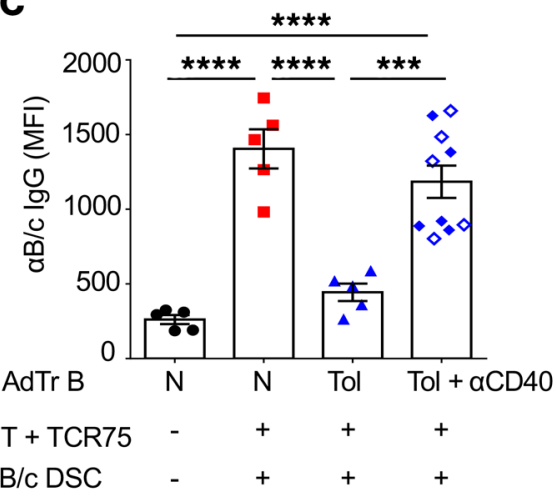

Figure 5. Donor-specific B cell tolerance is rapidly induced and prevented by agonistic anti-CD40 antibody. (A) Experimental designs for various treatments and AdTr models for B-F. (B) Immunization with third-party antigen C3H DSCs and analysis of anti-C3H IgC on day 14 (D14) (normalized MFI). $n=$ 5-6/group. (C) Agonistic anti-CD40 ( $\alpha$ CD40; $100 \mu$ g, i.v.) was administered at the time of HTx and treatment with $\alpha$ CD154 plus DSCs. On D14, enriched B cells from naive (N-B) or $\alpha$ CD40-treated tolerant (Tol-B) mice were AdTr into MD4 hosts and challenged with $2 \times 10^{7} \mathrm{~B} / \mathrm{c} \mathrm{DSCs}$. $\alpha \mathrm{B} / \mathrm{c} \mathrm{IgC}$ (MFI) was measured on D14 (open symbols) and D28 (filled symbols) after AdTr. (D) B6 mice transplanted with B/c heart graft were treated with CTLA-4lg (250 $\mu \mathrm{g} / \mathrm{mse}$, i.p.) on D0, D2, D4, and D7 after HTx. On D14, B cells were isolated and AdTr into MD4 recipients and immunized with $2 \times 10^{7} \mathrm{~B} / \mathrm{c} \mathrm{DSCs}$. $\alpha \mathrm{B} / \mathrm{c} \mathrm{IgG} \mathrm{(MFI)} \mathrm{measured}$ on D14 (open symbols) and D40 (filled symbols) after AdTr. $n=5-10 /$ group. (E) N-B or Tol-B cells were isolated from D7, D14, D35, and >D60 post-HTx recipients receiving $\alpha$ CD154 plus DSCs and AdTr to MD4 hosts. Filled and open symbols indicate $\alpha \mathrm{B} / \mathrm{c}$ IgG measured on D14 and D28 after AdTr, respectively. $n=6-16 /$ group. (F) Purified B cells $\left(2 \times 10^{7}\right)$ from naive B6 mice on D35 posttreated with $\alpha$ CD154 plus DSCs without HTx or tolerant mice D35 after HTx, were AdTr into MD4 hosts, followed by immunization with $2 \times 10^{7} \mathrm{~B} / \mathrm{c} \mathrm{DSCs} . \alpha \mathrm{B} / \mathrm{c}$ IgG (MFI) measured on day $28 . n=5 /$ group. MFIs were normalized to MD4 that received N-B cells without B/c DSCs. Data were pooled from 2 or more independent experiments. Data are presented as the mean $\pm S E M$. ${ }^{*} P<0.05 ;{ }^{* *} P<$ $0.001 ;{ }^{* * *} P<0.0001$ by 1-way ANOVA with Bonferroni's post hoc test.

hosts maintain their dysfunctional state in the presence of acute rejection, cognate $\mathrm{T}$ cell help, and direct activation by agonistic agents specific for CD40 and Toll-like receptor 9 (TLR-9).

Phenotypic analysis of AdTr tolerant B cells. We next compared the phenotype of the B cells following AdTr into MD4 recipients to identify the stage at which tolerant $B$ cells were unable to progress, even when T cell help was available. When AdTr naive B cells were analyzed on day 14 after AdTr, we observed that in MD4 hosts of naive $\mathrm{B}$ cells, $16 \%$ to $30 \%$ of naive $\mathrm{K}^{\mathrm{d}}$ - and $\mathrm{I}-\mathrm{E}^{\mathrm{d}}$-specific $\mathrm{B}$ cells had differentiated into GC B cells $\left(\mathrm{Fas}^{+} \mathrm{GL} 7^{+}\right)$, whereas this differentiation was significantly inhibited in hosts of tolerant $B$ cells (Figure 4, A-D). The proliferation of tolerant B cells and their expression of AID were also significantly reduced compared with naive B cells on day 14 after DSC immunization (Figure 4, E-H). To test whether tolerant $B$ cells were able to respond to antigen, we examined for the upregulation of CD69, Glut-1, and mitochondrial mass on day 3 after AdTr (Figure 4, I-N). These early markers of activation were comparably expressed in $\mathrm{AdTr}$ naive and tolerant alloreactive B cells, suggesting that tolerant B cells recognized and mounted early responses to alloantigen but were unable to differentiate into GC B cells.

$B$ cell tolerance induced by $C o B$ in $B / c$ HTx recipients is donor specific and rapidly induced. We next investigated the specificity of B cell tolerance and the conditions for its induction. First, we tested whether B cell tolerance was donor specific by performing $\mathrm{B}$ cell AdTr experiments into MD4 hosts immunized with $\mathrm{C} 3 \mathrm{H}$ mouse spleen cells. Host mice harboring naive or tolerant B cells produced comparable anti-C3H IgG, confirming the donor specificity of B cell tolerance (Figure 5, A and B). These observations, together with the recovery of comparable numbers of total, as well as alloreactive, B cells from hosts of naive or tolerant B cells (Supplemental Figure 4, A-C) suggest that AdTr naive and tolerant B cells engrafted equally and that tolerant donor-specific $B$ cells displayed persistent defects in their ability to accumulate and differentiate into GC B cells despite the availability of cognate Tfh help.

Second, we tested whether agonistic anti-CD40 antibody, administered at the time of HTx and $\mathrm{CoB} / \mathrm{DSC}$, could prevent the induction of B cell tolerance (Figure $5 \mathrm{C}$ ). Consistent with com- 
A

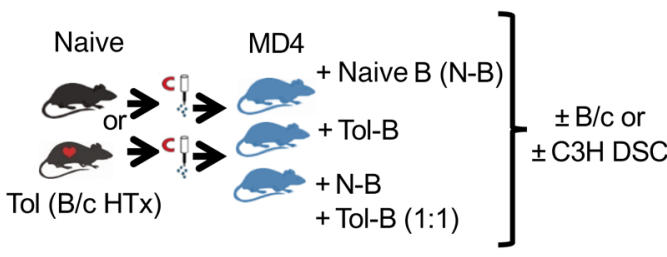

D

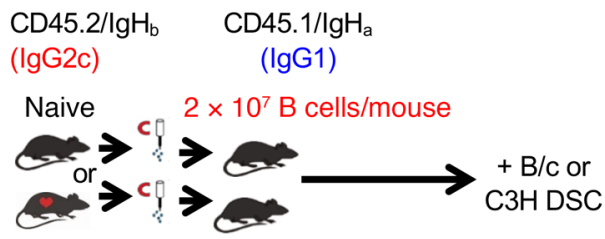

Tol (B/c HTx)
B

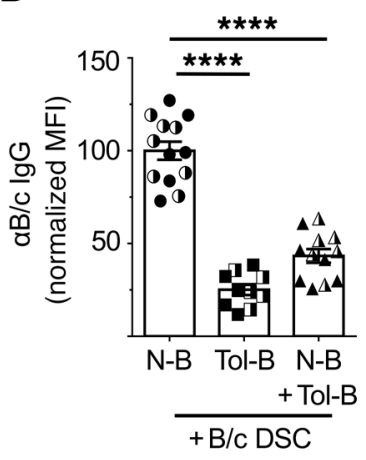

E

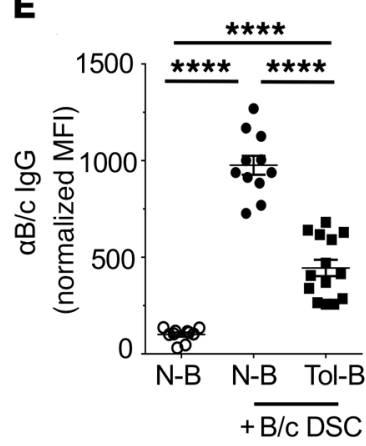

I

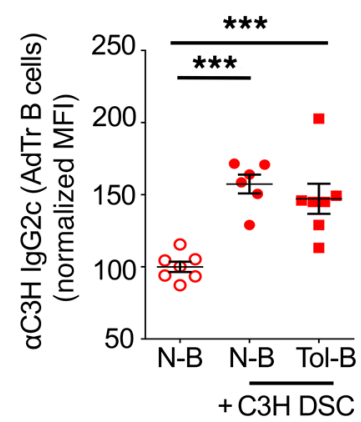

$\mathbf{L}$

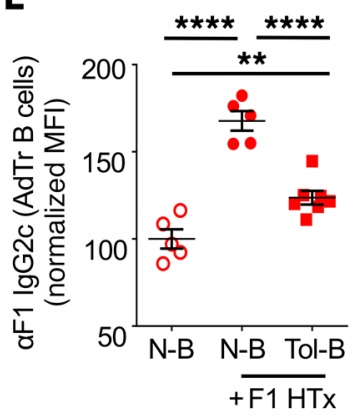

C

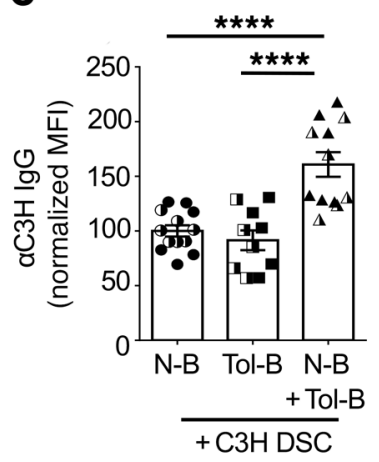

$\mathbf{F}$

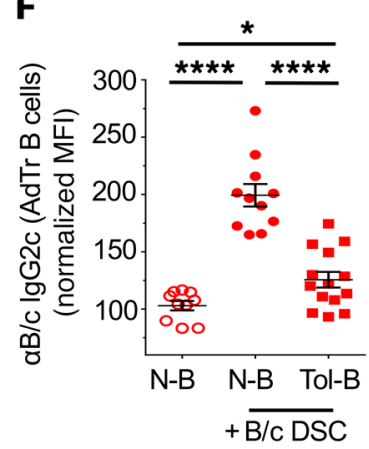

J

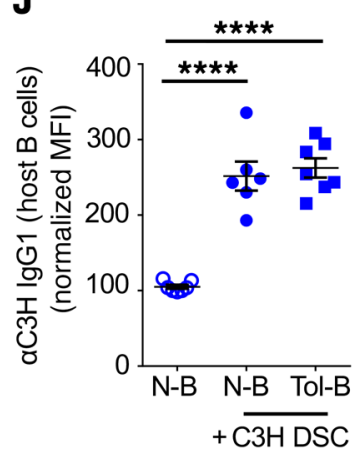

M

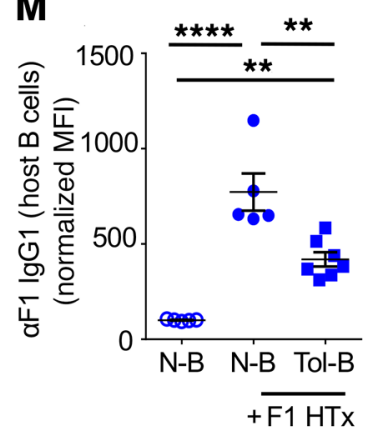

Figure 6. Donor-specific tolerant $B$ cells suppress naive $B$ cell responses in a donor-specific manner. (A) Experimental design. Enriched naive $B$ ( $N$ - $B$ ) or tolerant B (Tol-B) cells $\left(2 \times 10^{7}\right.$ each), or cotransfer of N-B and Tol-B cells $\left(2 \times 10^{7} \mathrm{~N}-\mathrm{B}+2 \times 10^{7}\right.$ Tol-B cells/mouse) together with $1 \times 10^{3}$ purified TCR75 T cells and $5 \times 10^{6}$ purified B6 T cells into MD4 recipients and then immunized with B/C or C3H DSCs the following day. (B and C) Normalized MFI of (B) anti-B/C $(\alpha \mathrm{B} / \mathrm{c}) \lg \mathrm{G}$ or $(\mathrm{C}) \alpha \mathrm{C} 3 \mathrm{H}$ IgG, measured on day 21 (D21; filled symbols) and D30 (half-filled symbols). $n=10-13 /$ group. (D) Experimental design. Enriched $\mathrm{N}$-B or Tol-B cells $\left(2 \times 10^{7}\right.$ each) from donor $\mathrm{CD} 45.2 / \mathrm{IgH}_{\mathrm{b}}$ mice were transferred into recipients $\mathrm{CD} 45.1 / \mathrm{lgH}$ and were immunized with $2 \times 10^{7} \mathrm{~B} / \mathrm{C}$ or $\mathrm{C3H} \mathrm{DSCs}$.

(E-G) Normalized MFI of $\alpha B / c(E)$ total IgG, (F) IgG2c produced by AdTr B cells, and (G) IgG1 produced by host B cells. $n=10-14 / g r o u p$. (H-J) Normalized MFI of $\alpha \mathrm{C} 3 \mathrm{H}(\mathbf{H})$ total IgG, (I) IgG2c from AdTr B cells, and (J) IgG1 produced by host B cells. $n=6-7 /$ group. (K) Experimental design. Enriched N-B or Tol-B cells $\left(2 \times 10^{7}\right.$ each) from donor $\mathrm{CD} 45.2 / \mathrm{lgH}$ mice were transferred into recipients $\mathrm{CD} 45.1 / \mathrm{lgH}$ that received F1 heart graft the following day. (L) $\alpha \mathrm{F} 1 \mathrm{lgC2c}$ from AdTr B cells or (M) $\alpha$ F1 IgG1 from host B cells. $n=5-7 /$ group. MFIs were normalized to MD4 or congenic mice that received N-B cells without B/c or C3H DSCs or F1 HTx. Data are pooled from 2 or more independent experiments. Data are presented as the mean $\pm \mathrm{SEM}$. ${ }^{*} P<0.05 ;{ }^{*} P<0.01 ;{ }^{* * *} P<0.001 ;{ }^{* * *} P<$ 0.0001 by 1-way ANOVA with Bonferroni's post hoc test. 
A

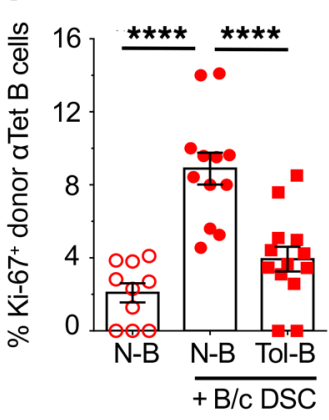

E

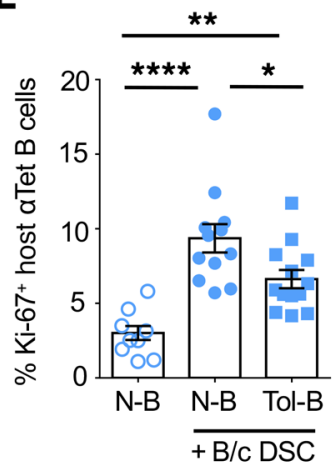

I

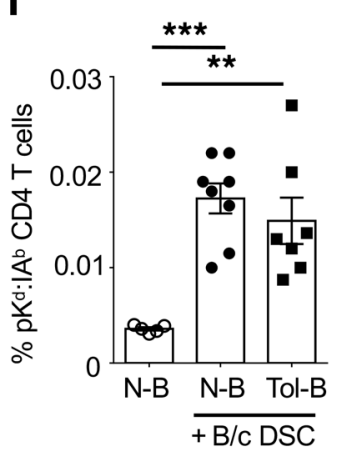

B

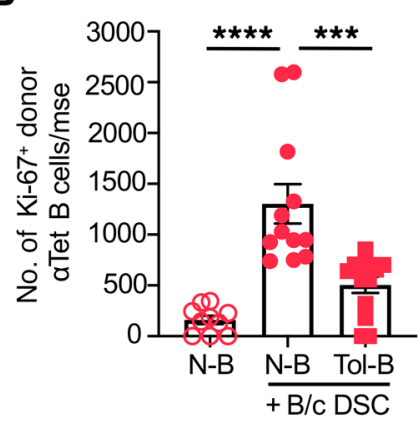

$\mathbf{F}$

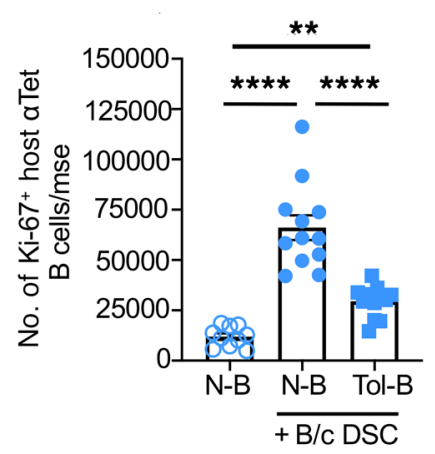

J

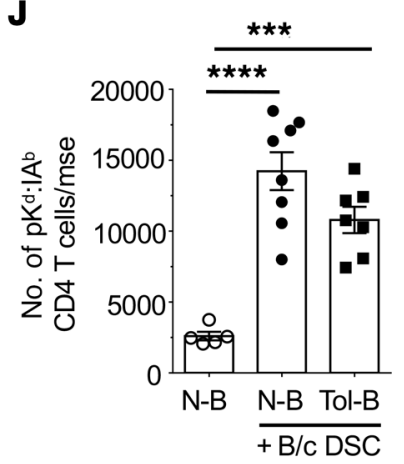

C

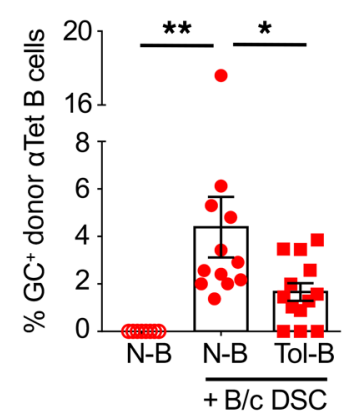

G

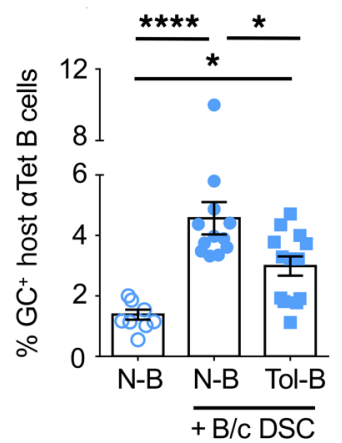

$\mathbf{K}$

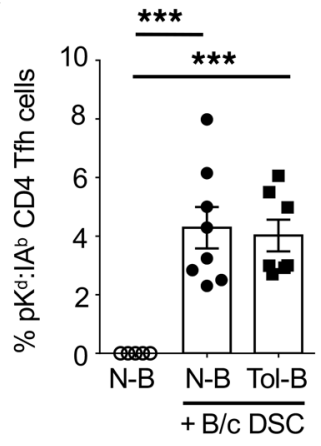

$\mathbf{N}$

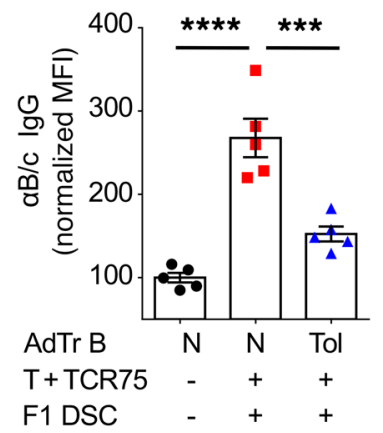

D

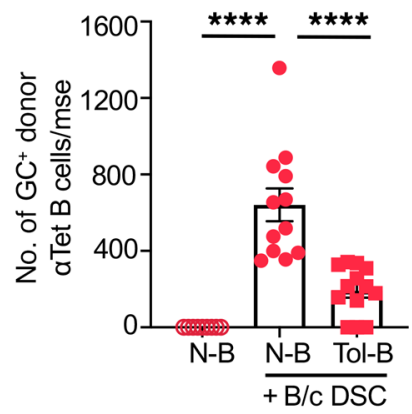

H

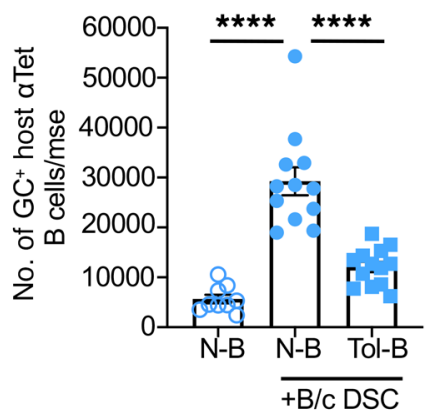

$\mathbf{L}$

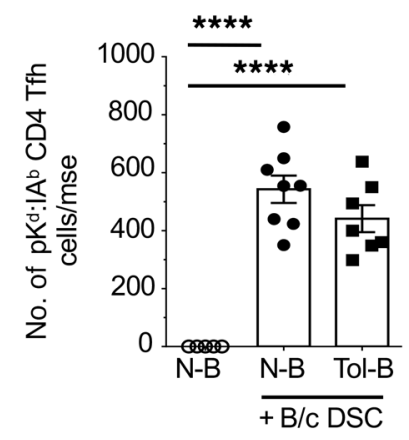

$\mathbf{0}$

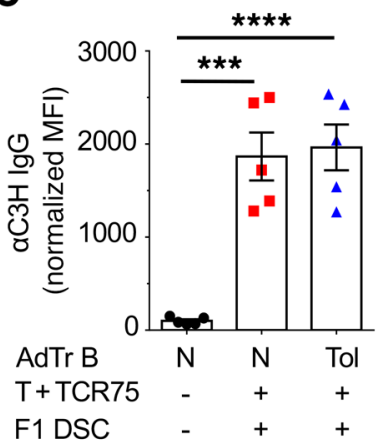


Figure 7. Alloreactive tolerant B cells suppress naive B cell proliferation and GC responses, but do not suppress donor-specific Tfh responses. Spleen and lymph nodes (inguinal, axillary, and branchial) were harvested from $\mathrm{CD} 45.1 / \mathrm{IgH}_{a}$ recipients receiving donor naive $\mathrm{B}(\mathrm{N}-\mathrm{B})$ or tolerant $\mathrm{B}$ (Tol-B) cells from $\mathrm{CD} 45.2 / \mathrm{IgH}_{b}$ immunized with $\mathrm{B} / \mathrm{C}$ DSCs and analyzed on days 14 to 21 after AdTr. (A) Percentage Ki-67+ donor anti-tetramer ( $\alpha \mathrm{Tet}$ ) $B$ cells. (B) Total number of Ki-67+ donor $\alpha$ Tet B cells/mouse (mse). (C) Percentage $\mathrm{GC}^{+}$donor $\alpha$ Tet B cells. (D) Total number of $\mathrm{GC}^{+}$donor $\alpha$ Tet B cells/ mouse. (E) Percentage Ki-67+ host $\alpha$ Tet $B$ cells. (F) Total number of Ki- $67^{+}$ host $\alpha$ Tet B cells/mouse. (G) Percentage GC+ host $\alpha$ Tet B cells. (H) Total number of $\mathrm{GC}^{+}$host $\alpha$ Tet $B$ cells/mouse. $n=9-13 /$ group. Data are pooled from more than 2 independent experiments. (I) Percentage $\mathrm{pK}^{\mathrm{d}}: \mathrm{I}^{\mathrm{b}} \mathrm{CD4^{+ }} T$ cells. (J) Total number of $\mathrm{pK}^{\mathrm{d}}: \mathrm{I}^{\mathrm{b}} \mathrm{CD} 4^{+} \mathrm{T}$ cells/mouse. (K) Percentage $\mathrm{pK} \mathrm{K}^{\mathrm{d}}: \mathrm{A}^{\mathrm{b}}$ CD4 ${ }^{+}$Tfh cells. (L) Total pK ${ }^{\mathrm{d}}: \mathrm{A}^{\mathrm{b}}$ CD4 ${ }^{+}$Tfh cells/mouse. $n=5-8 /$ group. Data are pooled from 2 or more independent experiments. (M) Experimental design. Enriched B cells $\left(2 \times 10^{7}\right)$ isolated from naive or Tol mice were transferred into MD4 hosts, followed by immunization with $\mathrm{F} 1(\mathrm{C} 3 \mathrm{H} \times \mathrm{B} / \mathrm{c}) \mathrm{DSCs}$. DSA-IgG was collected on day 14 after AdTr. ( $\mathbf{N}$ and $\mathbf{O}$ ) Normalized MFI of (N) $\alpha \mathrm{B} / \mathrm{c}$ IgG and (O) $\alpha \mathrm{C} 3 \mathrm{H}$ IgG produced by AdTr N-B or Tol-B cells. $n=5 /$ group. MFIs were normalized to MD4 mice that received N-B cells without $\mathrm{F} 1(\mathrm{C} 3 \mathrm{H} \times \mathrm{B} / \mathrm{C}) \mathrm{DSC}$. Data are pooled from 2 or more independent experiments and are presented as the mean $\pm \mathrm{SEM}$. ${ }^{*} P<0.05$; ${ }^{*} P<0.01$; ${ }^{* * *} P<$ $0.001 ;{ }^{* * *} P<0.0001$ by 1 -way ANOVA with Bonferroni's post hoc test.

parable expression of CD40 in naive and tolerant mice (Supplemental Figure 3, D and E), agonistic anti-CD40 induced allograft rejection and DSA production (Supplemental Figure 6), and prevented the development of $\mathrm{B}$ cell tolerance. Thus, the absence of direct CD40 signaling in APCs and/or alloreactive B cells is critical for inducing B cell tolerance.

To test if another mode of costimulation blockade could induce B cell dysfunction, B6 recipients received CTLA-4Ig (on days $0,2,4$, and 7) to induce HTx tolerance. We chose CTLA-4Ig because belatacept, a high-affinity mutant of human CTLA-4Ig, is approved for preventing rejection in kidney transplant patients (22). At 30 days or more after HTx and CTLA-4Ig, B cells were transferred into immunized MD4 hosts. Mice receiving B cells from CTLA-4Ig-treated recipients produced significantly less DSA-IgG compared with those receiving naive B cells (Figure 5D). Thus, CTLA-4Ig also induced alloreactive B cell tolerance.

We next assessed the kinetics of B cell tolerance induction, where B cells from tolerant recipients were harvested on days 7, 14, 35 , and $>60$ after HTx, and then AdTr into immunized MD4 hosts. By day 7 after HTx, B cells already exhibited partially dysfunctional properties and produced less DSA-IgG compared with naive $B$ cells; by day 14 after HTx, B/c-specific B cells were comparably dysfunctional as B cells from day 35 and $>60$ after HTx (Figure 5, $A$ and E). Finally, we show that the presence of allograft reinforced the tolerance-inducing regimen, as $\mathrm{B}$ cells from mice that received anti-CD154/DSC without B/c HTx produced significantly more anti-B/c IgG in MD4 hosts, compared with B cells from HTxtolerant mice (Figure $5 \mathrm{~F}$ ). These data suggest a rapid induction, and a contribution of the allograft, to the induction and/or maintenance of B cell tolerance.

Tolerant $B$ cells suppress naive $B$ cell responses in a donor-specific manner. In some experimental scenarios, $B$ cells can escape their anergic state if they are recruited into established GC responses (23). To test this possibility, we AdTr an equal mixture of naive and tolerant $\mathrm{B}$ cells $\left(2 \times 10^{7}\right.$ naive $+2 \times 10^{7}$ tolerant $\mathrm{B}$ cells/mouse $)$ into immunized MD4 mice (Figure 6A). In this experiment, serum anti-B/c IgG was not restored by the presence of graft-specific naive $\mathrm{B}$ cells (Figure 6B). In fact, the observation that serum anti$B / c \operatorname{IgG}$ was not equal to naive $B$ cell transfers alone raised the unexpected possibility that tolerant B cells dominantly inhibited naive $\mathrm{B}$ cell responses to B/c DSCs. This inhibition was donorspecific, as MD4 recipients receiving co-AdTr of naive and tolerant B cells and immunized with C3H DSCs produced significantly more anti-C3H IgG compared with mice receiving only naive or tolerant B cells (Figure 6C).

To confirm the suppressive ability of tolerant B cells, we developed a different AdTr model in which congenic (CD45.1, Igh ${ }_{\mathrm{a}}$ ) mice were hosts for AdTr B cells isolated from naive or tolerant B6 mice (CD45.2, Igh $_{\mathrm{b}}$ ). Host alloreactive B cells express an Ig allotype distinct from that of transferred tolerant $B$ cells, enabling us to separate IgG1 produced by host B cells from IgG2c produced by the AdTr B cells (quantification of IgG subclasses is limited to available allotype-specific reagents). Following AdTr of B cells (2 $\times 10^{7} /$ mouse) into congenic hosts and immunization (Figure 6D), anti-B/c was quantified on days 14 and 21 after immunization. In this environment of intact alloreactive $\mathrm{T}$ and $\mathrm{B}$ cell repertoires, recipients of tolerant $B$ cells produced significantly less total anti$\mathrm{B} / \mathrm{c}$ IgG compared with recipients of naive B cells (Figure 6E). Furthermore, tolerant AdTr B cells did not recover their ability to produce anti-B/c IgG2c, but instead inhibited anti-B/c IgG1 production by naive host B cells (Figure 6, F and G). Finally, we show that the suppression of antibody production was donor specific, as recipients of tolerant or naive $\mathrm{B}$ cells, when challenged with $\mathrm{C} 3 \mathrm{H}$ splenocytes, produced comparable anti-C3H IgG (Figure 6, H-J), consistent with the MD4 experiments above.

Finally, to test the robustness of B cell suppression, congenic mice that received AdTr naive or tolerant $B$ cells received an allogeneic $\mathrm{F} 1(\mathrm{~B} / \mathrm{c} \times \mathrm{B} 6) \mathrm{HTx}$ (instead of DSC immunization). In the absence of immunosuppression, HTx allografts were rejected in 10 to 12 days (data not shown), but the AdTr B cells remained unable to produce F1-specific IgG2c and suppressed anti-B/c IgG1 production by endogenous naive host B cells (Figure 6, K-M). Taken together, our data demonstrate that tolerant donor-specific $\mathrm{B}$ cells were arrested in their ability to differentiate into GC cells, and unexpectedly, exhibited a remarkably robust ability to suppress alloantibody production by naive donor-specific B cells, but not B cells with third-party specificity.

Tolerant B cells inhibit naive donor-specific B cell GC responses without inhibiting donor-specific Tfh responses. To assess the mechanism of tolerant B cell-mediated suppression of naive donorspecific $\mathrm{B}$ cells in congenic hosts, we examined their proliferation using Ki-67 expression, and their differentiation into $\mathrm{Fas}^{+} \mathrm{GL7}^{+} \mathrm{GC}$ $B$ cells. The percentage and total number of AdTr and host alloreactive $B$ cells expressing Ki- 67 and acquiring the GC phenotype were significantly reduced in congenic hosts receiving tolerant $B$ cells compared with hosts receiving naive B cells (Figure 7, A-H). These observations suggest that tolerant $B$ cells were able to suppress the proliferation of naive host $\mathrm{B}$ cells and their differentiation into GC B cells.

To test if donor-specific B cell suppression is mediated through the inhibition of donor-specific $\mathrm{T}$ cell responses and Th differentiation, we used $\mathrm{pK}^{\mathrm{d}} \mathrm{I} \mathrm{I}-\mathrm{A}^{\mathrm{b}}$ tetramers to identify endogenous $\mathrm{CD} 4^{+} \mathrm{T}$ 
cells with indirect specificity for donor-derived $\mathrm{H}-2 \mathrm{~K}^{\mathrm{d}}{ }_{54-68}$ peptide presented on host I- $\mathrm{A}^{\mathrm{b}}(24)$. Importantly these $\mathrm{pK}^{\mathrm{d}}: \mathrm{I}-\mathrm{A}^{\mathrm{b}}$-positive $\mathrm{T}$ cells can engage in a cognate manner with anti- $\mathrm{K}^{\mathrm{d}} \mathrm{B}$ cells. On days 14 to 21 after immunization, the percentages and total numbers of $\mathrm{pK}^{\mathrm{d}}: \mathrm{I}-\mathrm{A}^{\mathrm{b}} \mathrm{CD} 4^{+} \mathrm{T}$ cells, including those that were CXCR5 ${ }^{+} \mathrm{PD}-1^{+}$, in recipients of naive or tolerant $B$ cells were not significantly different (Figure 7, I-L). Thus, tolerant B cell-mediated suppression is not dependent on the inhibition of donor-specific Tfh cell accumulation; therefore, suppression by tolerant B cells appears to be distinct from classical Bregs that regulate $\mathrm{T}$ cell responses (25-28). Indeed, phenotypic analysis of donor-specific B cells from tolerant compared with naive mice revealed no enrichment of markers associated with transitional B cells (CD93, T1, T2, and T3), or Bregs (CD5/CD1d, Tim-1, and IL-10) (Supplemental Figure 7 and refs. $25,26,29)$.

A feature of transplantation tolerance is linked suppression, which is defined as the ability of $\mathrm{CD}^{+} \mathrm{T}$ cells tolerant to donor antigens to suppress $\mathrm{T}$ cells specific for third-party antigens, if they are presented on the same APCs presenting donor antigens $(30,31)$. To test whether B cell tolerance exhibited linked suppression, MD4 hosts of AdTr tolerant or naive B cells were challenged with $\mathrm{F} 1(\mathrm{~B} / \mathrm{c} \times \mathrm{C} 3 \mathrm{H})$ DSCs (Figure $7 \mathrm{M})$. As expected, anti-B/c IgG responses by tolerant $\mathrm{B}$ cells were significantly inhibited compared with responses by naive B cells; however, the anti-C3H IgG responses were comparable (Figure 7, $\mathrm{N}$ and $\mathrm{O}$ ). Therefore, tolerant B cells can mediate donor-specific, but not linked, B cell-to-B cell suppression.

\section{Discussion}

In this study, we show that alloreactive B cells, including those with higher affinity, were not deleted during transplantation tolerance induced by CoB. Early BCR signaling events were preserved (increased CD69, Nur77, IRF4, and Glut-1 expression as well as increased cell size), but tolerant B cells were unable to undergo GC differentiation and produce DSA. This was evident even when the B cells were removed from the tolerogenic environment and AdTr into naive hosts with a normal complement of alloreactive $\mathrm{T}$ and $\mathrm{B}$ lymphocytes. Transferred tolerant B cells also expressed early activation markers consisting of increased CD69, Glut-1, mitochondrial mass, and cell size, and exhibited lower proliferation and expression of AID, and were arrested in GC B cell differentiation even in the presence of cognate $\mathrm{T}$ cell help. Rapid $\mathrm{B}$ cell proliferation requires increased metabolism that is achieved in part by glucose import through Glut-1, and increased oxidative TCA metabolism associated with increased mitochondrial mass (18). Thus, the phenotype of tolerant B cells is consistent with a cell-intrinsic block after metabolic reprogramming and before entry into the GC. A more detailed definition of the checkpoint at which tolerant B cells are maintained will require molecular analysis at steady state in tolerant recipients, and upon adoptive transfer and challenge with donor antigen in the presence of cognate $\mathrm{T}$ cell help.

Dysfunctional or anergic autoreactive B cells are potentially pathogenic, and recent reports suggest the potential value of retaining these self-reactive B cells (32-35). In our studies, tolerant B cells were unable to differentiate into DSA-producing cells, but served as APCs to stimulate alloreactive T cells. We reason that potential advantages must outweigh the risk of maintaining tolerant alloreactive B cells. First, tolerant B cells may indirectly contribute to the stability of tolerance by serving as APCs to elicit protective $\mathrm{T}$ cell immunity during infections that may otherwise abrogate tolerance and induce allograft rejection $(3,36)$. For example, when an allograft becomes infected with Epstein Barr virus (EBV) or polyoma BK virus, tolerant alloreactive B cells may capture shed cell membrane fragments bearing donor and viral antigens, and process and present virus-derived peptides to virus-specific $\mathrm{T}$ cells that mediate protective immunity. This ability of tolerant B cells to stimulate T cells contrasts with Bregs that inhibit $\mathrm{T}$ cell activation and promote Treg expansion through the production of immunosuppressive cytokines such as IL-10 and IL-35 $(28,37,38)$. As a result, Bregs may suppress antiviral $\mathrm{T}$ cell immunity or even induce antiviral $\mathrm{T}$ cell tolerance, and therefore, inadvertently promote allograft loss arising from infectionmediated allograft damage.

We additionally reason that the potential risk of maintaining tolerant B cells with the ability to stimulate $\mathrm{T}$ cells is mitigated if multiple mechanisms are constraining alloreactive T cells in transplantation tolerance (39). If donor-specific T cells are cell-intrinsically tolerant, cognate interaction with donor-specific B cells should not incite their activation. Conversely, if $\mathrm{T}$ cell tolerance becomes transiently abrogated $(36,40)$ and donor-reactive T cells become capable of providing help to B cells, intrinsically tolerant $B$ cells will not be able to differentiate into antibody-secreting cells (ASCs). Thus, when the infection is cleared and T cell tolerance is restored $(36,40)$, the recipient will not harbor long-lived plasma cells capable of producing pathogenic DSA that can lead to chronic injury and the eventual loss of the allograft. Finally, we demonstrate that tolerant B cells suppress naive donor-specific B cells in 3 different AdTr models. We hypothesize that donor-specific B cellmediated suppression is an important mechanism for controlling new alloreactive B cells emerging from the bone marrow, and thus provides the most compelling reason for their preservation in tolerant recipients. The precise mechanism of suppression, and whether this is due to direct B cell-to-B cell suppression or is mediated through a third cell type, remains to be clarified in future studies. Regardless, this ability of tolerant B cells to mediate donor-specific B cell suppression distinguishes tolerant B cells from anergic B cells that are also unable to mount normal B cell responses but are not known to have suppressive activities $(12,41-43)$.

Two key features of transplantation tolerance are infectious tolerance and linked suppression, where tolerant $\mathrm{CD} 4^{+} \mathrm{T}$ cells can "infect" naive T cells and render them tolerant in a donor-specific manner, and spread T cell tolerance to third-party and donor antigens presented by the same APCs $(30,31)$. Infectious tolerance and linked suppression are mediated by $\mathrm{FoxP}^{+}$Tregs inhibiting FoxP3- conventional T cells, either independently or downstream of Bregs $(25,26)$. Tolerant B cells can suppress naive donor-specific B cells, but cannot mediate linked suppression. We reason that each B cell presents only the donor antigens taken up by the BCR, and as a result can only engage in cognate interaction with $\mathrm{T}$ cells recognizing peptides derived from the donor antigen and presented on MHC class II. In contrast, dendritic cells can take up and present a wide array of donor antigens, and can therefore simultaneously engage with $\mathrm{T}$ cells with diverse donor-antigen specificity. 
As a consequence, the promiscuous interaction between Tregs and conventional $\mathrm{T}$ cells of different specificities with the same dendritic cells permits linked suppression.

The ability of tolerant donor-specific B cells to suppress naive $\mathrm{B}$ cells is reminiscent of Bregs that have the ability to suppress $\mathrm{T}$ cells. However, tolerant donor-specific B cells are not enriched for IL-10 production or other phenotypic markers associated with Bregs (Supplemental Figure 7). In fact, IL-10 has been reported to promote GC B cells, so canonical IL-10-producing Bregs should not directly suppress $B$ cell responses $(44,45)$. Inhibition of the cytokine B cell-activating factor (BAFF) can facilitate B cell tolerance (reviewed in ref. 46). Consistent with the lack of B cell deletion in this CoB/DSC model of tolerance, the levels of circulating BAFF were not reduced in tolerant recipients compared with naive mice, or in MD4 hosts receiving tolerant or naive $\mathrm{B}$ cells (Supplemental Figure 8). Finally, Wallace et al. (47) reported that $B$ cells suppress IgG responses via cell surface complexes formed between glycoprotein A repetitions predominant (GARP) and TGF- $\beta$. However, GARP expression is not upregulated in tolerant or suppressed B cells (Supplemental Figure 9). At present, the mechanism for donor-specific B cell-to-B cell infectious tolerance remains unknown. Tolerant $B$ cells may represent a subset of Bregs that specializes in controlling B cells, not dissimilar to Treg subsets preferentially inhibiting Th1, Th17, or Tfh responses (48-50). Testing if tolerant $\mathrm{B}$ cells and Bregs are part of a broader subset of $B$ cells and plasma cells that regulate select arms of adaptive immunity awaits the identification of a lineage-specific transcription factor for Bregs.

$\mathrm{T}$ follicular regulatory ( $\mathrm{Tfr}$ ) cells have been reported to regulate GC B cell responses, raising the possibility that B cell tolerance might be dependent on the effects of Tfr cells (reviewed in ref. 51). Herein, we demonstrate that mice lacking Tfr cells $\left(\mathrm{Bcl}^{\text {fl/fl}} \mathrm{Foxp}^{\mathrm{Cre}}[\mathrm{Bcl} \mathrm{FFC}]\right.$ mice$)(52,53)$ and treated with $\mathrm{CoB} /$ DSC were able to accept F1 allografts and did not develop DSAs (Supplemental Figure 10A). Furthermore, upon AdTr into MD4 hosts, B cells from tolerant Bcl6FC recipients remained intrinsically unable to produce DSAs (Supplemental Figure 10, B and C). We also did not observe differences in the frequencies of endogenous Tfr in MD4 recipients of naive versus tolerant B cells from WT mice (Supplemental Figure 10, D and E). These observations suggest that Tfrs are not necessary for the induction of $\mathrm{B}$ cell tolerance induced by $\mathrm{CoB}$ and murine heart transplantation.

In summary, our studies revealed that B cell tolerance is rapidly induced in the absence of costimulation and in the presence of an allogeneic heart. B cell tolerance is characterized by a cell-intrinsic inability to differentiate into DSA-producing cells, and a preserved ability to function as APCs to stimulate cognate $\mathrm{T}$ cell differentiation into Tfh cells. Unexpectedly, tolerant B cells were able to suppress naive $B$ cell production of IgG in an antigen-specific manner, providing a potential explanation for why these cells are maintained in tolerant recipients. Identifying the mechanisms of tolerant B cell dysfunction and suppression may lead new ways to control DSA production and promote long-term graft survival in the clinic.

\section{Methods}

Mice. Eight- to 12-week-old female C57BL/6 (B6, H-2 $)$ mice and 6- to 8 -week-old female BALB/c (B/c, $\left.\mathrm{H}-2^{\mathrm{d}}\right)$ mice were purchased from the
Jackson Laboratory or Harlan Laboratories. Act-2W-OVA-Tg mice on a B6 background (B6.2W-OVA) mice were a gift from James Moon (Massachusetts General Hospital, Harvard Medical School, Charlestown, Massachusetts, USA). Donor B/c.2W-OVA-Tg mice were backcrossed from B6-2W-OVA mice for more than 10 generations. 2W-OVA-Tg B6 mice were bred with $\mathrm{B} / \mathrm{c}$ mice to obtain $2 \mathrm{~W}$-OVA.F1 mice. $\mathrm{F} 1(\mathrm{C} 3 \mathrm{H} \times \mathrm{B} / \mathrm{c})$ were bred from $\mathrm{B} / \mathrm{c}$ males and $\mathrm{C} 3 \mathrm{H}$ females. HEL-specific Ig-Tg MD4 female mice were originally purchased from the Jackson Laboratory and were backcrossed to B6 for more than 10 generations. AID-Cre [B6; FVB-Tg (Aicda-cre)1 Rcas/J], ROSA26-EYFP mice [B6.129 × 1Gt(ROSA)26Sor, tm1(EYFP)Cos>/J], C57BL/6-Tg(Nr4a1-EGFP/cre) 820Khog/J (catalog 016617), C3H/HEN (C3H, H-2 $)$, and IL-10 reporter-knockin tiger mice were from the Jackson Laboratory. TCR75 TCR-Tg mice were obtained from R. Pat Bucy (University of Alabama-Birmingham) and crossed to CD45.1 mice. CD45.1/IgH $\mathrm{I}_{\mathrm{a}}$ congenic mice on a B6 background were bred in the animal facilities of the University of Chicago. Foxp3YFP$\mathrm{Cre}^{+} \mathrm{Bcl} 6^{\mathrm{f} / \mathrm{ll}}$ mice were crossed with $\mathrm{Bcl} 6^{\mathrm{f} / \mathrm{fl}}$ mice to generate Foxp3YFP$\mathrm{Cre}^{+} \mathrm{Bcl}^{\mathrm{fl} / \mathrm{l}}$ mice, as previously described $(52,53)$.

Heart transplantation. Heterotropic heart transplantations were performed as previously described (54), by grafting donors $\mathrm{B} / \mathrm{c}, \mathrm{B} / \mathrm{c}$ OVA, or 2W-OVA F1 hearts onto the inferior vena cava and aorta in the peritoneal cavity of female $\mathrm{B} 6, \mathrm{MD} 4$, or $\mathrm{CD} 45.1 / \mathrm{IgH}_{\mathrm{a}}$ congenic recipients. Tolerance (CoB/DSC) was induced with anti-CD154 antibody (MR1, BioXCell) at a dose of $500 \mu \mathrm{g}$ on day 0 (i.v.), and $250 \mu \mathrm{g}$ on days 7 and 14 (i.p.) after transplantation, in combination with $2 \times 10^{7}$ DSCs on day 0. CTLA-4Ig (Abatacept, Bristol-Myers Squibb) was used at a dose of $250 \mu \mathrm{g}$ /mouse (i.p.) on days 0, 2, 4, and 7 after heart transplantation. In some experiments, tolerant mice received $100 \mu \mathrm{g}$ (i.v.) of agonistic anti-CD40 antibody (FGK4.5, BioXCell) on days 0 and 7 after transplant. Graft survival was assessed by palpation every other day, and the day of rejection was defined as the last day of detectable heartbeat.

HLA tetramers. Biotinylated $\mathrm{H}-2 \mathrm{~K}^{\mathrm{d}}, \mathrm{I}-\mathrm{E}^{\mathrm{d}}, \mathrm{H}-2 \mathrm{~L}^{\mathrm{d}}$, and $\mathrm{H}-2 \mathrm{~K}^{\mathrm{b}}$ monomers, and $\mathrm{H}-2 \mathrm{~K}^{\mathrm{d}}, \mathrm{I}-\mathrm{E}^{\mathrm{d}}$, and $\mathrm{H}-2 \mathrm{~L}^{\mathrm{d}}$ tetramers conjugated with $\mathrm{PE}$ or APhC were obtained from the NIH Tetramer Core Facility. The peptide bound to $\mathrm{H}-2 \mathrm{~K}^{\mathrm{d}}$ tetramers was SYIPSAEKI from the malarial parasite Plasmodium berghei. $\mathrm{IE}^{\mathrm{d}}$ tetramers were loaded with pConsCDR1 (FIEWNKLRFRQGLEW) peptide, $\mathrm{H}-2 \mathrm{~L}^{\mathrm{d}}$ tetramers were loaded with MuLV gp70 mimotope synthetic peptide MNTYAYHML, and $\mathrm{K}^{\mathrm{b}}$ tetramers were loaded with SIINFEKL $\left(\mathrm{OVA}_{257-264}\right)$. Endogenous $\mathrm{pK}^{\mathrm{d}}: \mathrm{I}-\mathrm{A}^{\mathrm{b}}$ tetramer ${ }^{+} \mathrm{T}$ cells recognize the $\mathrm{K}^{\mathrm{d}}{ }_{54-68}$ peptide (QEGPEYWEEQTQRAK), which is an immunodominant epitope of the $\alpha 1$-chain of the class I molecule $\mathrm{K}^{\mathrm{d}}$ (NIH Tetramer Core Facility). The decoy tetramer was created in-house in which the core fluorochrome, SA-PE (Prozyme), was conjugated to AF647 (Life Technologies) for 60 minutes at room temperature. Free AF647 was removed by centrifugation in a $100-\mathrm{kDa}$ molecular weight cutoff Amicon Ultra filter (Millipore). The SA-PE-AF647 complex concentration was calculated and adjusted to $1 \mu \mathrm{M}$ by measuring the absorbance of PE at $566 \mathrm{~nm}$. The SA-PE-AF647 complex was then incubated with 6-fold molar excess of biotinylated $\mathrm{H}-2 \mathrm{~K}^{\mathrm{b}}$ (SIINFEKL) monomers for 30 minutes at room temperature. For tetramer staining, a single-cell suspension was prepared and resuspended in PBS containing 2\% FBS, Fc block anti-CD16/32 (2.4G2), and Fixable Aqua Live/Dead (Thermo Fisher Scientific). Decoy tetramer was added at a concentration of 5 to $10 \mathrm{nM}$ and incubated at $4^{\circ} \mathrm{C}$ for 10 minutes before addition of PE-conjugated $\mathrm{K}^{\mathrm{d}}, \mathrm{I}-\mathrm{E}^{\mathrm{d}}$, and/or $\mathrm{L}^{\mathrm{d}}$ tetramer and incubated on ice for 30 minutes. For all other tetramers, tetramer staining was performed for 30 minutes 
at room temperature before the addition of monoclonal antibodies for phenotyping. For $5 \times 10^{6}$ cells, saturating concentrations of $\mathrm{K}^{\mathrm{d}}$, I-E $\mathrm{d}$, or $\mathrm{L}^{\mathrm{d}}$ tetramer $(0.1 \mu \mathrm{g})$, and $\mathrm{pK}^{\mathrm{d}}: \mathrm{I}-\mathrm{A}^{\mathrm{b}}$ tetramer $(0.5 \mu \mathrm{g})$ were used.

Cell enrichment and adoptive transfer. Single-cell suspensions from spleens and pooled lymph nodes (branchial, inguinal, axillary) of B6, tolerant ( $\geq$ POD 60 ), or TCR75 TCR-Tg mice were prepared. The following biotinylated antibodies were used for $\mathrm{B}$ or $\mathrm{T}$ cell enrichment by negative selection: anti-CD4 (GK1.5, catalog 100404, BioLegend), anti-CD8a (53-6.7, catalog 100704, BioLegend), anti- $\gamma \delta$ TCR (eBioGL3, catalog 13-5711-85, Invitrogen), anti-F4/80 (BM8, catalog 123106, BioLegend), anti-49b (DX5, 108904, BioLegend), anti-NK1.1 (PK136, catalog 108704, Invitrogen), anti-CD11b (M1/70, catalog 101204, BioLegend), anti-CD11c (N418, catalog 117304, BioLegend), anti-Ly-6G/Ly-6C (RB6-8C5, catalog 108404, BioLegend), antiCD19 (6D5, catalog 115504), and anti-IgMb (AF6-78, catalog 406204, BioLegend). Cells were incubated for 20 minutes at $4^{\circ} \mathrm{C}$ followed by washing before incubating with streptavidin magnetic beads for 10 minutes at room temperature (catalog 88817 , Thermo Fisher Scientific). Labeled cells were separated using a magnetic particle concentrator (Dynal, Invitrogen). Purity of both B cells and T cells was greater than $95 \%$, as determined by flow cytometry using a BD LSR II. In other experiments, murine B cells were enriched using a Pan-B Cell Isolation Kit (Miltenyi Biotec), while $\mathrm{CD}^{+} \mathrm{T}$ cells were isolated by negative selection using the CD4 T Cells Isolation Kit (Miltenyi Biotec). For AdTr studies, $2 \times 10^{7}$ naive or tolerant B cells, $5 \times 10^{6} \mathrm{~B} 6 \mathrm{~T}$ cells, and $1 \times 10^{3} \mathrm{CD}^{+}{ }^{+}$TCR75 cells were administered i.v. into MD4 recipients followed by immunization with or without $\mathrm{B} / \mathrm{c}, \mathrm{C} 3 \mathrm{H}$, or $\mathrm{F} 1(\mathrm{C} 3 \mathrm{H} \times \mathrm{B} / \mathrm{c})$ DSCs. In other experiments, $2 \times 10^{7}$ naive or tolerant $\mathrm{B}$ cells only were injected i.v. into $\mathrm{CD} 45.1 / \mathrm{IgH}_{\mathrm{a}}$ recipients.

DSA quantification. $\mathrm{B} / \mathrm{c}, \mathrm{F} 1$, or $\mathrm{C} 3 \mathrm{H}$ DCSs were harvested and their red blood cells were lysed with $2 \mathrm{~mL}$ ammonium chloridepotassium (ACK) lysing buffer for 2 minutes (Quality Biological). DSCs $\left(1 \times 10^{6}\right)$ were incubated with $3 \mu \mathrm{L}$ of serum from naive, sensitized, transplanted, or MD4 recipients for 1 hour at $4^{\circ} \mathrm{C}$. Then the cells were washed and incubated with anti-CD19 (1D3, catalog 550992, BD Biosciences), goat anti-mouse IgG (H+L) (catalog 103102, Southern Biotech), IgG2c (catalog 1079-02, Southern Biotech), or biotinylated mouse anti-mouse IgG1[a] (10.9, catalog 553500, $\mathrm{BD}$ Pharmingen) for 30 minutes at $4^{\circ} \mathrm{C}$, and in certain experiments, FITC-conjugated streptavidin (catalog 554060, BD Biosciences) was added as secondary antibody for 20 minutes. MFIs of the CD19 $\mathrm{IgG}^{+}$cells were measured by flow cytometry using a BD LSR II and BD FACSDiva software v8.0.2.

Antibodies and flow cytometry. Samples were prepared with approximately $1 \times 10^{7}$ cells per tube. The following antibodies were used for surface staining at $4^{\circ} \mathrm{C}$ : CD49b (DX5, catalog 485971-82, Invitrogen), CD11b (M1/70, catalog 101224, BioLegend), CD11c (N418, catalog 48-0114-82, eBioscience), NK1.1 (PK136, catalog 48-5941-82, eBioscience), Ter-119 (Ter-119, catalog 48-5921-82, eBioscience), F4/80 (BM8, catalog 48-4801-82, Invitrogen), CD19 (eBio1D3, catalog 48-0193-82, eBioscience), CD3 (17A2, catalog 48-0032-82, eBioscience), B220 (RA3-6B2, catalog 563103, BD Biosciences), IgD (1126c.2a, catalog 405716, BioLegend), Fas (Jo2, catalog 557653, BD Biosciences), T and B Cells Activation Antigen (GL7, catalog 553666, BD Biosciences), CD80 (16-10A1, catalog 104721, BioLegend), CD69 (H1.2F3, catalog 104520 and catalog 104541, BioLegend), IgM (II/41, catalog 743325, BD Biosciences), IgG (polyclonal, catalog 46-4010-
82, Invitrogen), CD90.2 (53-2.1, catalog 47-0902-82, Invitrogen), CD4 (RM4-5, catalog 563106, BD Biosciences), CD45.1 (A20, catalog 45-0453-82, eBioscience), CD45.2 (104, catalog 47-0454-80, Invitrogen), V $\beta 8.3$ (1B3.3, catalog 553664, BD Biosciences), CXCR5 (L138D7, catalog 145503, BioLegend), PD-1 (J43, catalog 46-9985-80, eBioscience), GARP (YG1C86, catalog 46-9891-82, Invitrogen), CD93 (AA4.1, catalog 136512, BioLegend), TIM-1 (RMT1-4, catalog 119505, BioLegend), CD5 (53-7.3, catalog 25-0051-81, eBioscience), CD1d (IB1, catalog 17-0011-82, Invitrogen), CD21 (7E9, catalog 123418, BioLegend), CD23 (B3B4, catalog 25-0232-82, eBioscience), and CD40 (3/23, catalog 561845, BD Pharmingen). For intracellular staining, samples were fixed with a Foxp3 Fix/Perm buffer set according to the manufacturer's instruction (eBioscience). Samples were then intracellularly stained with antibodies against Ki-67 (B56, catalog 561283, BD Biosciences), Glut-1 (EPR3915, ab195359, Abcam), Nur77 (12.14, catalog 46-5965-82, eBioscience), IRF4 (3E4, catalog 25-9858-82, eBioscience), and Foxp3 (FJK-165, catalog 53-5773-82, Invitrogen). For mitochondrial mass staining, cells were incubated 20 minutes at $37^{\circ} \mathrm{C}$ with $200 \mathrm{nM}$ MitoTracker Green (catalog M7514, Invitrogen) to measure mitochondrial content. All cell samples were run on a BD LSR II flow cytometer or LSRFortessa HTS, both with BD FACSDiva v8.0.2 software. In certain experiments, cells were sorted on a BD FACSAria lllu with BD FACSDiva v6.1.3.

Drug treatment. Mice received $100 \mu$ (i.v.) CpG ODN 1826 (type B) (catalog IAX-200-002, Innaxon) on day 0, $50 \mu \mathrm{g} \mathrm{CpG} \mathrm{(i.p.)} \mathrm{on} \mathrm{days}$ 1 and 2, and $100 \mu$ g (i.v.) agonistic anti-CD40 (FGK4.5, BioXCell) on days 0 and 7 .

In vitro stimulation assay. Single-cell suspensions were prepared from spleens and peripheral lymph nodes from naive, AR, or tolerant Nur77GFP mice and then incubated with decoy tetramers as described above. The cells were then enriched with Anti-PE MicroBeads (catalog 130-048-801, Miltenyi Biotec) before flow sorting. Sorted I-E ${ }^{\mathrm{d}}-$ $\mathrm{Neg}, \mathrm{I}-\mathrm{E}^{\mathrm{d}}-\mathrm{Lo}$, and $\mathrm{I}-\mathrm{E}^{\mathrm{d}}-\mathrm{Hi} \mathrm{B}$ cells were plated for subsequent in vitro stimulation assays. Briefly, 96-well tissue culture plates (catalog CLS 3595 , Corning) were coated with $100 \mu \mathrm{L}$ of purified streptavidin (cata$\log 280302$, BioLegend) $(5 \mu \mathrm{g} / \mathrm{mL})$ prepared in $1 \times$ PBS and incubated overnight at $37^{\circ} \mathrm{C}$. For the rest of the procedure, plates were washed with $0.05 \%$ (vol/vol) Tween 20 (Sigma-Aldrich) in PBS. Biotinylated I- $E^{\mathrm{d}}$ monomer $(100 \mu \mathrm{L}$ of $1 \mu \mathrm{g} / \mathrm{mL})$ was added and incubated at room temperature for 2 hours and washed. Sorted B cells were cultured in complete RPMI 1640 (catalog 112-024-101, Quality Biological Inc.) in tissue culture plates uncoated or coated with streptavidin-bound biotinylated monomer. Anti-IgM F(ab') ${ }_{2}$ (catalog 115-006-020, Jackson ImmunoResearch Laboratories) was added to the wells loaded with Tet-Neg B cells to be used as a positive control. Plates were then incubated at $37^{\circ} \mathrm{C}$ and harvested after 6 or 12 hours. The cells were then stained for CD69, Nur77, and IRF4, as described above.

Flow cytometric analysis of intracellular IL-10 production. Purified B cells from WT naive, naive, and tolerant IL-10.GFP reporter mice were resuspended $\left(2 \times 10^{6}\right.$ cells $\left./ \mathrm{mL}\right)$ in RPMI 1640 medium containing 10\% FBS, $200 \mu \mathrm{g} / \mathrm{mL}$ penicillin, $200 \mathrm{U} / \mathrm{mL}$ streptomycin, $4 \mathrm{mM}$ L-glutamine, $5 \times 10^{-5} \mathrm{M} 2-\mathrm{ME}$ (all from Life Technologies) with LPS (10 $\mu \mathrm{g} / \mathrm{mL}$, Escherichia coli serotype 0111:B4, Sigma-Aldrich), ionomycin (500 ng/mL, Sigma-Aldrich), PMA (50 ng/mL, Sigma-Aldrich), and monensin $(2 \mu \mathrm{M}$, eBioscience) for 8 to 10 hours in incubator as previously described (29). IL-10 was detected by EGFP reporter expression. Cells from WT littermates were used as negative controls. 
$B A F F$ ELISA. The BAFF levels in mouse serum were measured by using a mouse BAFF/BLys/TNFSF13B Quantikine ELISA (R\&D Systems), with a 5-fold dilution of samples according to the manufacturer's instructions. Each sample was tested in duplicate, and the average value is reported as picograms per milliliter. The plates were read on a SpectraMax i3x microplate reader (Molecular Devices).

Statistics. Statistical analyses were performed using GraphPad Prism version 6. Sample sizes of 5 to 10 or more animals per experiment were chosen to ensure adequate power. Two-tailed unpaired Student's $t$ test was used to calculate differences between experimental animals. One-way analysis of variance (ANOVA) with Bonferroni's post hoc test or 2-way ANOVA with Tukey's post hoc test for multiple comparisons, or, where appropriate, nonparametric Mann-Whitney or Kruskal-Wallis with Dunn's post hoc test were performed to determine significance of differences between groups. Graft survival significance was assessed using a Kaplan-Meier/Mantel-Cox log-rank test. $P$ values below 0.05 were considered to indicate significant difference: ${ }^{*} P<0.05 ;{ }^{* *} P<0.01$; ${ }^{* *} P<0.001 ;{ }^{* * * *} P<0.0001$.

Study approval. All animal experiments were approved by the Institutional Animal Care and Use Committee at the University of Chicago, and adhered to the standard of NIH Guide for the Care and Use of Laboratory Animals (National Academies Press, 2011).

\section{Author contributions}

SHWK, DJ, JC, JY, and JSY conducted the experiments and analyzed the data. DY performed the heart transplants. AD provided the Foxp3YFPCre ${ }^{+} \mathrm{Bcl}^{\mathrm{fl} / \mathrm{fl}}$ mice. SHWK participated in writing the manuscript. RS and MLA provided critical feedback to the study design, and ASC designed the study and wrote the manuscript. All authors edited and provided feedback on the manuscript.

\section{Acknowledgments}

This work was supported in part by grants (1R01AI110513, P01AI097113) from the National Institute of Allergy and Infectious Diseases (NIAID) at the NIH. JSY was supported by American Heart Association Enduring Hearts Fellowship grant (15POST25700452) and NIH Respiratory Biology Training Grant T32 HL07605. JY was a recipient of an American Society of Transplantation TIRN (Transplantation and Immunology Research Network) Predoctoral Scholarship. MHC class I and II tetramers were provided by the NIH Tetramer Core Facility (contract HHSN272201300006C).

Address correspondence to: Anita S. Chong, PhD, Section of Transplantation, Department of Surgery, University of Chicago, 5841 South Maryland Ave, Chicago, Illinois 60636, USA. Phone: 773.702.5521; Email: achong@surgery.bsd.uchicago.edu.

JC's present address is: AstraZeneca, South San Francisco, California, USA.

JY's present address is: Department of Organ Transplantation, Shanghai ChangZheng Hospital, Second Military Medical University, Shanghai, China.

JSY's present address is: Bristol-Myers Squibb, Princeton, New Jersey, USA.
1. Loupy A, Lefaucheur C. Antibody-mediated rejection of solid-organ allografts. $N$ Engl J Med. 2018;379(12):1150-1160.

2. Burns AM, et al. Memory alloreactive B cells and alloantibodies prevent anti-CD154mediated allograft acceptance. J Immunol. 2009;182(3):1314-1324.

3. Kawai $\mathrm{T}$, et al. Long-term results in recipients of combined HLA-mismatched kidney and bone marrow transplantation without maintenance immunosuppression. Am J Transplant. 2014;14(7):1599-1611.

4. Li Y, Ma L, Shen J, Chong AS. Peripheral deletion of mature alloreactive $B$ cells induced by costimulation blockade. Proc Natl Acad Sci US A. 2007;104(29):12093-12098.

5. Braun U, Rajewsky K, Pelanda R. Different sensitivity to receptor editing of $\mathrm{B}$ cells from mice hemizygous or homozygous for targeted Ig transgenes. Proc Natl Acad Sci U S A. 2000;97(13):7429-7434.

6. Moon JJ, et al. Naive CD4(+) T cell frequency varies for different epitopes and predicts repertoire diversity and response magnitude. Immunity. 2007;27(2):203-213.

7. Li Y, Ma L, Yin D, Shen J, Chong AS. Longterm control of alloreactive $\mathrm{B}$ cell responses by the suppression of T cell help. J Immunol. 2008;180(9):6077-6084.

8. Parsons RF, et al. Acquisition of humoral transplantation tolerance upon de novo emergence of
B lymphocytes. J Immunol. 2011;186(1):614-620.

9. Moon JJ, et al. Tracking epitope-specific T cells. Nat Protoc. 2009;4(4):565-581.

10. Chen J, et al. Reversing endogenous alloreactive B cell GC responses with anti-CD154 or CTLA4Ig. Am J Transplant. 2013;13(9):2280-2292.

11. Yang J, et al. Tracing donor-MHC class II reactive b cells in mouse cardiac transplantation: delayed CTLA4-Ig treatment prevents memory alloreactive B-cell generation. Transplantation. 2016;100(8):1683-1691.

12. Taylor JJ, et al. Deletion and anergy of polyclonal B cells specific for ubiquitous membrane-bound self-antigen. J Exp Med. 2012;209(11):2065-2077.

13. Taylor JJ, Pape KA, Jenkins MK. A germinal center-independent pathway generates unswitched memory B cells early in the primary response. JExp Med. 2012;209(3):597-606.

14. Mason DY, Jones M, Goodnow CC. Development and follicular localization of tolerant B lymphocytes in lysozyme/anti-lysozyme IgM/IgD transgenic mice. Int Immunol. 1992;4(2):163-175.

15. Moran AE, et al. T cell receptor signal strength in Treg and iNKT cell development demonstrated by a novel fluorescent reporter mouse. J Exp Med. 2011;208(6):1279-1289.

16. Zikherman J, Parameswaran R, Weiss A. Endogenous antigen tunes the responsiveness of naive B cells but not T cells. Nature. 2012;489(7414):160-164.

17. Sciammas R, Li Y, Warmflash A, Song Y, Dinner
AR, Singh H. An incoherent regulatory network architecture that orchestrates B cell diversification in response to antigen signaling. Mol Syst Biol. 2011;7:495.

18. Caro-Maldonado A, et al. Metabolic reprogramming is required for antibody production that is suppressed in anergic but exaggerated in chronically BAFF-exposed B cells. J Immunol. 2014;192(8):3626-3636.

19. Honjo K, Xu Xy, Bucy RP. CD4+ T-cell receptor transgenic $\mathrm{T}$ cells alone can reject vascularized heart transplants through the indirect pathway of alloantigen recognition. Transplantation. 2004;77(3):452-455.

20. Chen J, Wang Q, Yin D, Vu V, Sciammas R, Chong AS. Cutting edge: CTLA-4Ig inhibits memory B cell responses and promotes allograft survival in sensitized recipients. Jimmunol. 2015;195(9):4069-4073.

21. Miller ML, et al. Distinct graft-specific TCR avidity profiles during acute rejection and tolerance. Cell Rep. 2018;24(8):2112-2126.

22. Vincenti F. Belatacept and long-term outcomes in kidney transplantation. $N$ Engl J Med. 2016;374(26):2600-2601.

23. Turner JS, Benet ZL, Grigorova IL. Antigen acquisition enables newly arriving B cells to enter ongoing immunization-induced germinal centers. J Immunol. 2017;199(4):1301-1307.

24. Ali JM, et al. Diversity of the CD4 T cell alloresponse: the short and the long of it. Cell Rep. 
2016;14(5):1232-1245.

25. Stolp J, Turka LA, Wood KJ. B cells with immune-regulating function in transplantation. Nat Rev Nephrol. 2014;10(7):389-397.

26. Ding Q, et al. Regulatory B cells are identified by expression of TIM- 1 and can be induced through TIM-1 ligation to promote tolerance in mice. JClin Invest. 2011;121(9):3645-3656.

27. Fillatreau S. Regulatory plasma cells. Curr Opin Pharmacol. 2015;23:1-5.

28. Shen P, et al. IL-35-producing B cells are critical regulators of immunity during autoimmune and infectious diseases. Nature. 2014;507(7492):366-370.

29. Matsushita T, Yanaba K, Bouaziz JD, Fujimoto M, Tedder TF. Regulatory B cells inhibit EAE initiation in mice while other B cells promote disease progression. J Clin Invest. 2008;118(10):3420-3430.

30. Honey K, Cobbold SP, Waldmann H. Dominant tolerance and linked suppression induced by therapeutic antibodies do not depend on Fas-FasL interactions. Transplantation. 2000;69(8):1683-1689.

31. Qin S, et al. "Infectious" transplantation tolerance. Science. 1993;259(5097):974-977.

32. Rosenspire AJ, Chen K. Anergic B cells: precarious on-call warriors at the nexus of autoimmunity and false-flagged pathogens. Front Immunol. 2015;6:580.

33. Sabouri Z, et al. Redemption of autoantibodies on anergic B cells by variable-region glycosylation and mutation away from self-reactivity. Proc Natl Acad Sci U S A. 2014;111(25):E2567-E2575.

34. Reed JH, Jackson J, Christ D, Goodnow CC. Clonal redemption of autoantibodies by somatic hypermutation away from self-reac- tivity during human immunization. JExp Med. 2016;213(7):1255-1265.

35. Burnett DL, et al. Germinal center antibody mutation trajectories are determined by rapid self/foreign discrimination. Science. 2018;360(6385):223-226.

36. Miller ML, et al. Spontaneous restoration of transplantation tolerance after acute rejection. Nat Commun. 2015;6:7566.

37. Fillatreau S, Sweenie CH, McGeachy MJ, Gray D, Anderton SM. B cells regulate autoimmunity by provision of IL-10. Nat Immunol. 2002;3(10):944-950.

38. Weber M, et al. Donor and host B cell-derived IL-10 contributes to suppression of graftversus-host disease. Eur J Immunol. 2014;44(6):1857-1865.

39. Miller ML, et al. Tracking of TCR-transgenic T cells reveals that multiple mechanisms maintain cardiac transplant tolerance in mice. Am J Transplant. 2016;16(10):2854-2864.

40. Young JS, et al. Erosion of transplantation tolerance after infection. Am J Transplant. 2017;17(1):81-90.

41. Getahun A, Beavers NA, Larson SR, Shlomchik MJ, Cambier JC. Continuous inhibitory signaling by both SHP-1 and SHIP-1 pathways is required to maintain unresponsiveness of anergic B cells. J Exp Med. 2016;213(5):751-769.

42. Duong BH, et al. Peripheral B cell tolerance and function in transgenic mice expressing an IgD superantigen. JImmunol. 2010;184(8):4143-4158.

43. Sabouri Z, et al. IgD attenuates the IgM-induced anergy response in transitional and mature $\mathrm{B}$ cells. Nat Commun. 2016;7:13381.

44. Laidlaw BJ, et al. Interleukin-10 from $\mathrm{CD}^{+}$follicular regulatory $\mathrm{T}$ cells promotes the germinal cen- ter response. Sci Immunol. 2017;2(16):eaan4767.

45. Xin G, et al. Single-cell RNA sequencing unveils an IL-10-producing helper subset that sustains humoral immunity during persistent infection. Nat Commun. 2018;9(1):5037.

46. Jackson SW, Davidson A. BAFF inhibition in SLE-Is tolerance restored? Immunol Rev. 2019;292(1):102-119.

47. Wallace $\mathrm{CH}$, et al. B lymphocytes confer immune tolerance via cell surface GARP-TGF- $\beta$ complex. JCI Insight. 2018;3(7):99863.

48. Koch MA, Tucker-Heard G, Perdue NR, Killebrew JR, Urdahl KB, Campbell DJ. The transcription factor $\mathrm{T}$-bet controls regulatory $\mathrm{T}$ cell homeostasis and function during type 1 inflammation. Nat Immunol. 2009;10(6):595-602

49. Joller N, et al. Treg cells expressing the coinhibitory molecule TIGIT selectively inhibit proinflammatory Th1 and Th17 cell responses. Immunity. 2014;40(4):569-581.

50. Sage PT, et al. Suppression by $\mathrm{T}_{\mathrm{FR}}$ cells leads to durable and selective inhibition of B cell effector function. Nat Immunol. 2016;17(12):1436-1446.

51. Sage PT, Sharpe AH. T follicular regulatory cells. Immunol Rev. 2016;271(1):246-259.

52. $\mathrm{Wu} \mathrm{H}$, et al. Follicular regulatory $\mathrm{T}$ cells repress cytokine production by follicular helper T cells and optimize IgG responses in mice. Eur J Immunol. 2016;46(5):1152-1161.

53. Hollister $\mathrm{K}$, et al. Insights into the role of Bcl6 in follicular Th cells using a new conditional mutant mouse model. J Immunol. 2013;191(7):3705-3711.

54 . Young JS, et al. Delayed cytotoxic T lymphocyte-associated protein 4 -immunoglobulin treatment reverses ongoing alloantibody responses and rescues allografts from acute rejection. $A m \mathrm{~J}$ Transplant. 2016;16(8):2312-2323. 